\title{
The influence of deck flexibility on the dynamic response of road bridges
}

\section{A influência da flexibilidade do tabuleiro na resposta dinâmica de pontes rodoviárias curvas}

E. P. SCHMIDT

erikaschmidt37@gmail.com

C. E. N. MAZZILLI a cenmazzi@usp.br

\begin{abstract}
A simplified methodology is proposed for the dynamic analysis of curved road bridges under the effect of a $3 \mathrm{C}$ class heavy vehicle. The dynamic models of both vehicle and bridge are considered to be uncoupled, being bound by the interaction forces. These forces come from the vehicle dynamic analysis, initially under rigid deck, subjected to a support excitation caused by the pavement geometric irregularities. Such forces are statically condensed in the vehicle centre of gravity and applied to a simplified structural model (unifilar) of a curved bridge with box girder section, considering the bridge superelevation. The influence of the rigid deck hypothesis on the dynamic response is assessed by an iterative procedure, in which the deck displacements are added to the pavement irregularities, to obtain an "equivalent irregularity" function. The new interaction forces are re-applied to the bridge model to determine new displacements, repeating the procedure until the results converge.
\end{abstract}

Keywords: dynamic analysis, curved road bridges, geometric irregularities.

\section{Resumo}

Uma metodologia simplificada é proposta para a análise dinâmica de pontes curvas sob o efeito de um veículo pesado classe $3 C$. Os modelos dinâmicos do veículo e da ponte são considerados separadamente, sendo vinculados pelas forças de interação. Essas forças são provenientes da análise dinâmica do veículo, inicialmente sobre tabuleiro rígido, submetido a uma excitação de suporte causada pelas irregularidades geométricas do pavimento. Tais forças são condensadas no centro de gravidade do veículo e aplicadas em um modelo estrutural simplificado (unifilar) de uma ponte em seção celular, considerando-se a superelevação da ponte. A influência da hipótese de tabuleiro rígido na resposta dinâmica é avaliada utilizando-se um procedimento iterativo, no qual se somam os deslocamentos do tabuleiro à irregularidade do pavimento, para se obter uma função de "irregularidade equivalente". As novas forças de interação são reaplicadas no modelo da ponte para determinar novos deslocamentos, repetindo-se o processo até a convergência dos resultados.

Palavras-chave: análise dinâmica, pontes rodoviárias curvas, irregularidades geométricas.

\footnotetext{
Polytechnic School, Department of Structural and Geotechnical Engineering, University of São Paulo, São Paulo, SP, Brasil.
} 


\section{Introduction}

Road bridges are important elements of a country's infrastructure, influencing its socio-economic development associated with road transport, especially in countries with deficiency in others types of transport, such as rail. (Santos [1])

The development of the road traffic in Brazil led to an increase in its volume and weight of vehicles. The combination of these factors with the development of increasingly slender structures and track irregularities characteristics, leads to an important variation of the stress amplitudes and amplification of the vibration frequency spectrum, these being relevant factors for the deterioration and reduction of the lifespan of road pavements and structures. (Santos [1])

According to Almeida [2], the appearance of early deterioration signs is a result of inappropriate design criteria. According to the author, the most severe actions transmitted to the bridge deck are caused by the occurrence of superficial irregularities, corresponding in extreme situations, related to lower quality pavements, to more than fifteen times those admitted in the design.

The occurrence of vibration phenomena in bridges, induced by vehicular traffic, had already been observed during the middle of the 19th century, due to the appearance of increasingly fast and heavy vehicles. The first studies on dynamic problems date from 1849 and it is an approach of Willis [3]: an equation of motion was deduced based on a model formed by a mass, moving with constant velocity on a massless and flexible simply-supported beam. Stokes [4], in the same year, obtained the exact solution of this equation, by employing a series expansion technique.

Krylov (apud Melo [5]) considered a load with negligible mass as compared to the beam, thus assessing the equivalent problem of a constant force moving over the structure.

In 1934, Inglis [6] proposed approximate solutions, obtained numerically for the model, assuming that the dynamic response of a simply-supported beam has the shape of its first mode of vibration, reducing the problem to only one generalized degree of freedom.

Timoshenko [7] analysed the problem of an impulsive load with constant velocity on a railway bridge. The author took into account the mass of the beam, the dynamic characteristics of the vehicle and the effects produced by the unbalanced wheels of locomotives.

With the development of computational tools after the 1950s and especially with the use of the Finite Element Method (FEM) from the 1970s onwards, the analysis of bridge vibrations could be done in more sophisticated ways. Vehicle-structure interaction is often approached using vehicle analytical models such as mass-springdamper oscillators to formulate the motion equations of the vehicle-structure coupled system. This will also be the approach used in this work, yet with its own characteristics.

In fact, Huang and Veletsos [8] already simulated the vehicle as a rigid body (mass) supported by a spring- damper system (vehicle suspension) in 1970. In Brazil, such a model was also employed by Bruch [9] to the analysis of the dynamic behaviour of rectangular plates with moving load; by Carneiro [10] for the analysis of beams with various support conditions, using stiffness and damping matrices variable with the vehicle position; and by Ferreira [11] to verify the effects of moving loads on the road bridge decks.
Chang and Lee [12] employed a simplified vehicle model with two degrees of freedom to evaluate the behaviour of simply supported bridges with a single span and came to the conclusion that normative codes tend to underestimate the impact coefficient, especially in the case of wide-span bridges.

Novak [13] concluded that dynamic loads do not depend only on the span, as shown by the normative impact coefficient expressions, but also depend on the pavement roughness surface and the dynamic characteristics of the vehicle.

Traditionally, dynamic loadings have been modelled by "equivalent" static loadings, in which impact coefficients are used. However, according to Melo [5], the adoption of impact coefficients applied to static loads, generally based on geometric aspects (length of the span), proves to be insufficient to meet the criteria of excessive cracking, excessive vibrations and deformations or, even, implying the reduction of the safety margin of the structure.

Melo [5], using an analytical-numerical model, used a five degreeof-freedom system for a three-axle heavy vehicle and evaluated the dynamic amplification factors in terms of displacements, in small-span bridges, due to traffic of heavy vehicles.

In the same year, Santos [1] developed a computational tool for three-dimensional mathematical-numerical modelling, considering the dynamic interaction between vehicle, rough pavement and structure.

Further, Moroz [14] developed a nine-degree-of-freedom (DOF) vehicle model by introducing the roll movement (rotation about the longitudinal axis) to the eight DOF vehicle that had already been used in the modelling of $3 \mathrm{C}$ class vehicle. The author made use of the static condensation methodology into the vehicle centre of mass of the contact forces between the tires and the pavement, in order to apply them to a simplified structural model of the bridge, herewith termed 'unifilar' model.

In the study of the structural dynamic response it is extremely important to consider the data regarding the actual traffic in the road networks, as well as the state of conservation of the pavements (Moroz [14]).

Rossigali [15] carried out a statistical study of several variables of the vehicles currently present in the country's highways, such as vehicle classification, wheelbase, axle loads, among others. Considering this, it was possible to create a reduced base of vehicle data in which the effects of the passage of these vehicles were analysed in representative bridges of the Brazilian road network. Finally, the author compared these effects to the corresponding standard vehicles of the existing Brazilian standards.

More recently, Rossigali [16] updated his database from the analysis of five road data sources. This database was used to simulate the traffic in typical bridges of the Brazilian road network, contributing to the modernization of vehicle load standards in Brazil.

Therefore, the use of more realistic models is necessary for a more consistent design of bridge structures.

This work aims at presenting a simplified methodology for the dynamic analysis of curved bridges under the effect of a class $3 \mathrm{C}$ heavy vehicle. This methodology considers the uncoupling of the vehicle and bridge models, only bounded by the interacting forces, being at the same time simple and accessible to structural engineers, using a commercially available finite element program. The bridge and vehicle models are studied using the dynamic 
modelling software ADINA - Automatic Dynamic Incremental Nonlinear Analysis [17], available in the Computational Mechanics Laboratory of the Polytechnic School of the University of São Paulo. For the dynamic analysis the Newmark's numerical integration method in the time domain will be used.

The preference for time-domain analysis in relation to frequencydomain analysis is associated with its greater generality, since it can be used in situations where the superposition of effects is not legitimate, as in non-linear studies.

The methodology begins with the modal analysis of the vehicle of class $3 \mathrm{C}$, according to Moroz [14], with the nine degrees-of-freedom, as well as the modal analysis of the bridge and calibration of the Rayleigh damping. Next, the geometric irregularities of the pavement (main cause for the time variation of the contact forces) are modelled by means of the spectral density function proposed by Honda [18]. With the consideration of rigid deck and pavement roughness, the dynamic response under the support excitation is carried out, which supplies the contact forces on the wheels. The contact forces are then statically condensed into the centre of mass of the vehicle and applied to the 'unifilar' model of the bridge, considering the super elevation of the deck and the eccentricity of the vehicle axis with respect to the bridge axis. In the 'unifilar' model the structure is modelled as a reticulated system in which only the axis of the box girder section and the columns are represented with 3D beam elements.

Given that the bridge is curved, an additional horizontal force is applied to the model: the centrifugal force. The centrifugal force can be added to the interaction forces from the dynamic analysis of the vehicle as the vehicle has only vertical damp- ers and the lateral stiffness of the tires are neglected. All these forces produce a moving load that travels along the bridge at a constant velocity.

The dynamic analysis of the bridge is then carried out subjected to the moving loading, resulting in temporal displacement functions for each node of the model. The nodal displacements at the instant the vehicle centre of mass is right at the same node are added to the local pavement roughness, generating the new "equivalent irregularity functions". These functions are applied to the vehicle model, resulting in new contact forces and the process is repeated until convergence is achieved.

\section{Modelling}

\subsection{Vehicular modelling}

As mentioned previously, Rossigali [16] analysed the frequency of vehicles in five databases, namely DNIT (1999-2002), CENTRAN (2005), Ecovias (2008), AutoBan (2008) and AutoBan (2011). In most of the bases, except for Ecovias (2008), the vehicle of class 3C was the one with the highest frequency, being $36.62 \%$ in the DNIT base (1999-2002), $28.35 \%$ in the base of the CENTRAN (2005), $21.86 \%$ at Autoban (2008) and $19.45 \%$ at Autoban (2011).

Thus, it can be concluded that the vehicle of class $3 \mathrm{C}$ is the most common among heavy vehicles. This vehicle has been used in this work. As discussed previously, this work considered the nine-degree-offreedom vehicle proposed by Moroz [14]: bounce of the suspended and non-suspended masses, and rotations around the longitudinal axis (roll) and transverse axis (pitch). The parameters used are

\section{Table 1}

Car mechanical and dynamic parameters

\begin{tabular}{|c|c|c|}
\hline Parameter & Value & Unit \\
\hline Vehicle suspended mass - $m v$ & 20.60 & $t$ \\
\hline Inertia moment of mass in roll $-I x x$ & 15.00 & t. $\mathrm{m}^{2}$ \\
\hline Inertia moment of mass in pitch - lyy & 65.00 & $t . m^{2}$ \\
\hline Front tire mass (non-suspended mass) - mpd & $0.32 \dagger$ & $\dagger$ \\
\hline Rear tire mass (non-suspended mass) - mpt & $0.53 t$ & $t$ \\
\hline Front suspension system stiffness - kvd & 432.00 & $\mathrm{kN} / \mathrm{m}$ \\
\hline Rear suspension system stiffness - kvt & 585.00 & $\mathrm{kN} / \mathrm{m}$ \\
\hline Front tire stiffness - kpd & 840.00 & $\mathrm{kN} / \mathrm{m}$ \\
\hline Rear tire stiffness - kpt & 1680 & $\mathrm{kN} / \mathrm{m}$ \\
\hline Front suspension system damping - cvd & 3.00 & $\mathrm{kNs} / \mathrm{m}$ \\
\hline Rear suspension system damping - cvt & 6.00 & $\mathrm{kNs} / \mathrm{m}$ \\
\hline Front tire damping $-c p d$ & 1.00 & $\mathrm{kNs} / \mathrm{m}$ \\
\hline Rear tire damping - cpt & 1.00 & $\mathrm{kNs} / \mathrm{m}$ \\
\hline Distance $d l$ & 4.00 & $\mathrm{~m}$ \\
\hline Distance $d 2$ & 0.80 & $\mathrm{~m}$ \\
\hline Distance d3 & 2.00 & $m$ \\
\hline Distance $d 4$ & 1.10 & $\mathrm{~m}$ \\
\hline
\end{tabular}



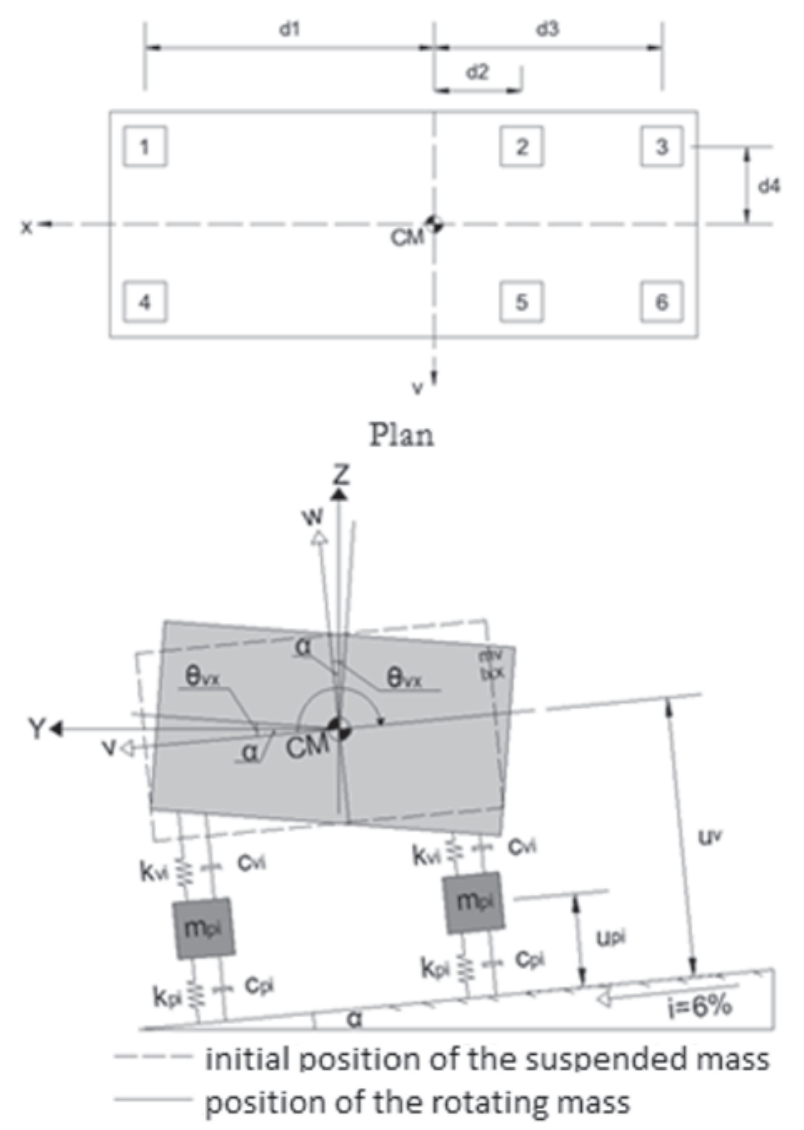

Transversal Section

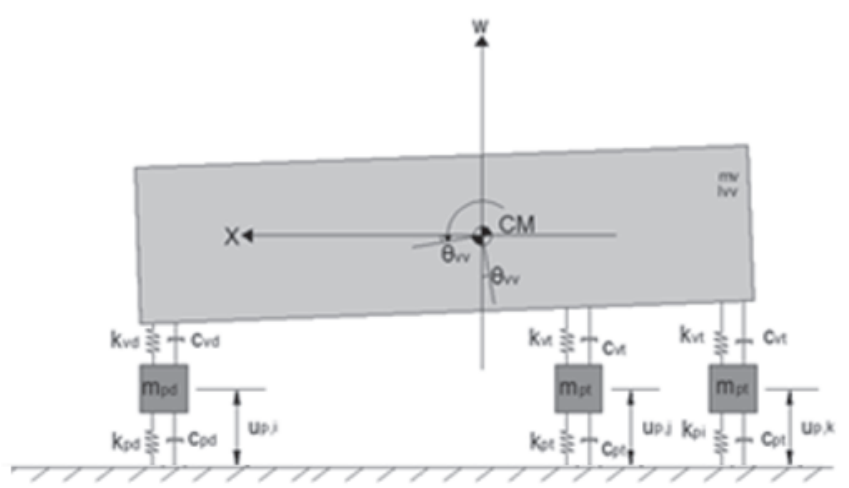

Longitudinal Section

\section{Figure 1}

Vehicle model

the same as those adopted by Santos [1] and Moroz [14], and are presented in table 1. Figure 1 shows the vehicle model used.

The vehicle will be modelled considering the local axes $v$ and $w$, in other words, the displacements of the vehicle $\left(u_{v}\right)$ and the tires $\left(u_{p, i}\right)$ are perpendicular to the deck surface. Therefore, the vehicle interaction forces should be decomposed according to the super elevation so, only then, the interaction forces can be applied in the unifilar model of the bridge.
Given that the bridge is curved, an additional horizontal force is applied to the model: the centrifugal force. The centrifugal force can be added to the interaction forces from the dynamic analysis of the vehicle, as the vehicle has only vertical dampers and the lateral stiffness of the tires are neglected. All these forces produce a moving load that travels along the bridge at a constant velocity.

Once the centrifugal force $(\mathrm{Fc})$ is applied to the centre of mass of the suspended mass, it is necessary to know the height of the centre of mass with respect to the pavement, in order to obtain the associated transport moment. This height was found in Ejzenberg [19], which considers a distance of $2.16 \mathrm{~m}$ for heavy trucks loaded. This distance was adopted in this work.

\subsection{Structural modelling}

For the study to be carried out in the later chapters, a bridge of the 900 branch of the Anhanguera complex will be analysed. The bridge has four curved spans (100m, 125m, 125m, 100m) and two straight $40 \mathrm{~m}$ spans, as shown in figure 2 . The radius of curvature in plan is constant and equal to $234.5 \mathrm{~m}$.

The structure is made of concrete, with box girder section of variable height in the curved stretches, it being higher in the region of the supports. After the curved sections there is a joint in the P4 column, which separates them from the two straight spans. These latter ones have cross section with constant height until the encounter E2.

In the model, the properties of all sections were considered, according to the height variation shown. Figure 3 shows the properties and dimensions of the sections of the support (a) and the middle of the span (b) of the curved section. For the straight spans the section is the same as in figure 3 (b).

The super elevation of the bridge varies from $2 \%$ to $6 \%$, as shown in figure 4. For purposes of study, it was used only the maximum super elevation of $6 \%$. In the P2 and P3 columns the superstructure has an eccentricity of $90 \mathrm{~cm}$ in relation to the column. In column P4 this eccentricity increases to $92.5 \mathrm{~cm}$.

It was considered a linear model for concrete, with compressive strength equivalent to $50 \mathrm{MPa}$ for superstructure, $40 \mathrm{MPa}$ for meso-structure and $25 \mathrm{MPa}$ for infra-structure.

The modelling of the analysed structure was done in the software ADINA - Automatic Dynamic Incremental Nonlinear Analysis [17].

The superstructure, columns and stakes were modelled with $3 \mathrm{D}$ bar elements, with properties equivalent to the respective sections. The blocks were modelled with shell elements, with thickness

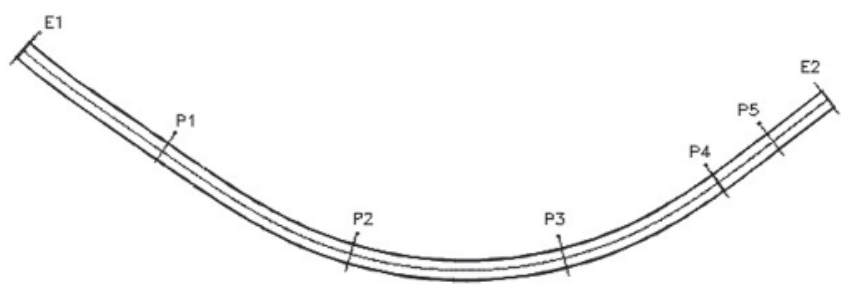

Figure 2

Bridge plan (drawing supplied by EGT Engenharia) 


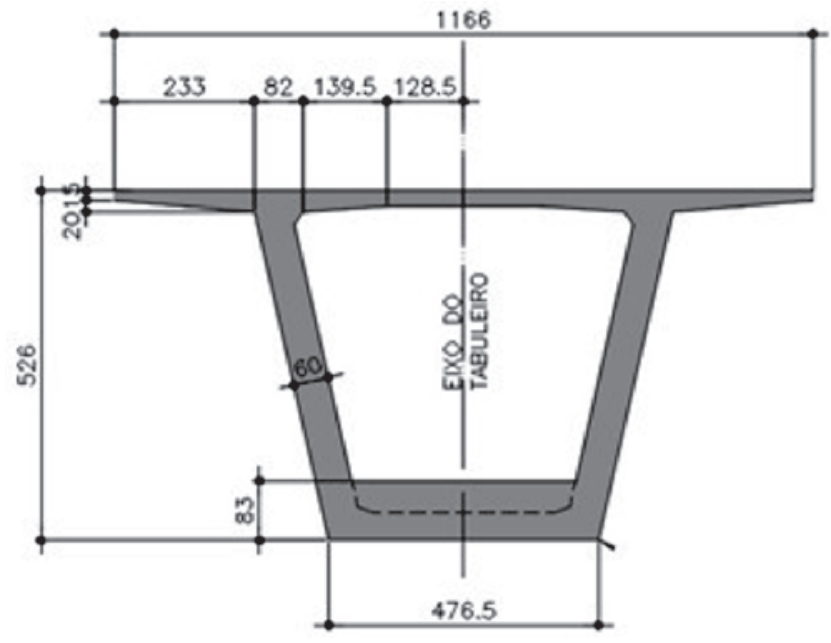

\begin{tabular}{|l|l|}
\hline$A\left(m^{2}\right)$ & 13.53 \\
\hline$I x\left(m^{4}\right)$ & 63.12 \\
\hline Iy $\left(m^{4}\right)$ & 83.24 \\
\hline It $\left(m^{4}\right)$ & 81.94 \\
\hline
\end{tabular}

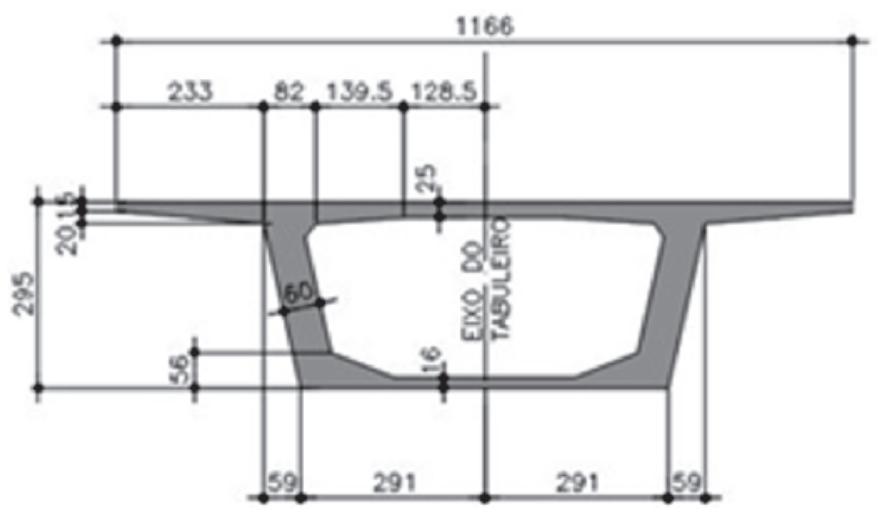

\begin{tabular}{|l|l|}
\hline $\mathrm{A}\left(\mathrm{m}^{2}\right)$ & 7.578 \\
\hline $\mathrm{Ix}\left(\mathrm{m}^{4}\right)$ & 8.93 \\
\hline $\mathrm{Iy}(\mathrm{m}$ & 63.91 \\
\hline $\mathrm{It}\left(\mathrm{m}^{4}\right)$ & 18.48 \\
\hline
\end{tabular}

\section{Figure 3}

Dimensions and properties of the cross-sections: (a) at the support (b) at the middle of the span (drawing supplied by EGT Engenharia)

equivalent to the height of the blocks, since they have less computational cost than solid elements and well represent the rigidity of the blocks. For the purpose of evaluating the displacements of the super-structure, it was considered sufficient to model the stakes to a depth of $2 \mathrm{~m}$ from the bottom of the block.

The supporting devices were modelled using bars, with the corresponding degrees of freedom at their end. Rigid links were used to connect the support devices to the super-structure and to the columns. To simulate the super elevation of the bridge, given by the slope of the box girder section, the local systems of the 3D bars that model the superstructure were rotated. Figure 7 shows the 'unifilar' model of the bridge.

\subsection{Pavement roughness profile}

A profile of random irregularities can be described mathematically by means of spectral density functions, obtained experimentally. The roughness spectrum of the pavement adopted in this work was calibrated by Honda [18], it being expressed by eq. 1 .

$S\left(\omega_{k}\right)=\bar{\alpha} \cdot\left(\omega_{k}\right)^{-\beta}$

where $\bar{\alpha}$ depends on the state of conservation of the pavement, classified in five categories, according to the International Organization for Standardization (ISO); $\beta$ is the exponent that depends on the material the pavement is made of, equal to 2.03 for asphalt pavements and 1.85 for concrete pavements; $\omega_{k}$ is the wave frequency, defined as the inverse of the wavelength.

According to Rossigali [16], among the various standardized scales that can be adopted as a measure of pavement irregularity, a widely used worldwide reference to denote pavement quality as a function of the roughness rate is the International Roughness Index (IRI). The correlation between ISO standards and the classification scale adopted by DNIT as a function of IRI is presented in table 2. 


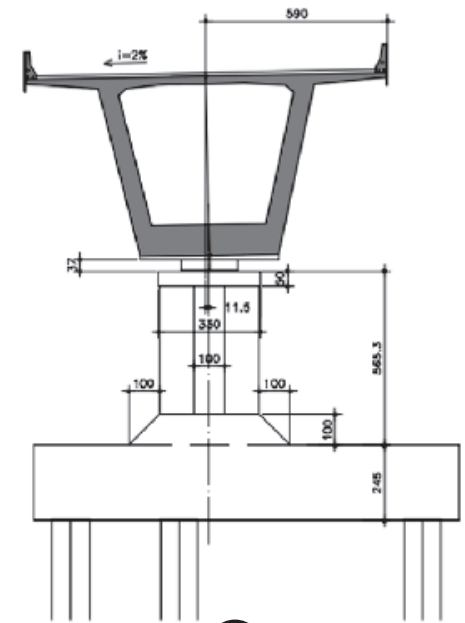

A

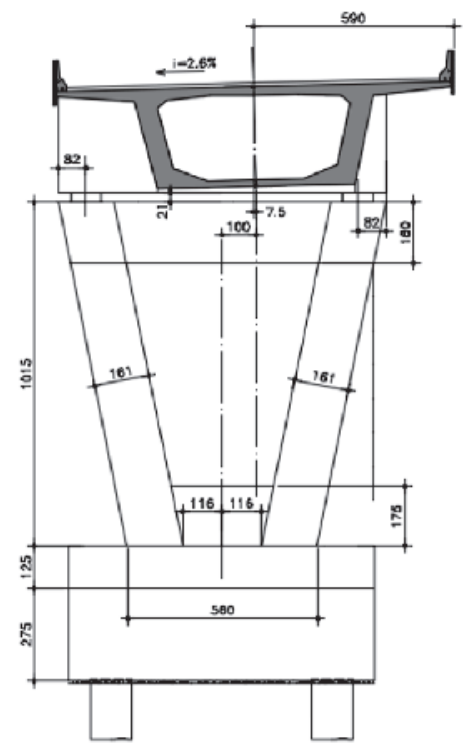

C

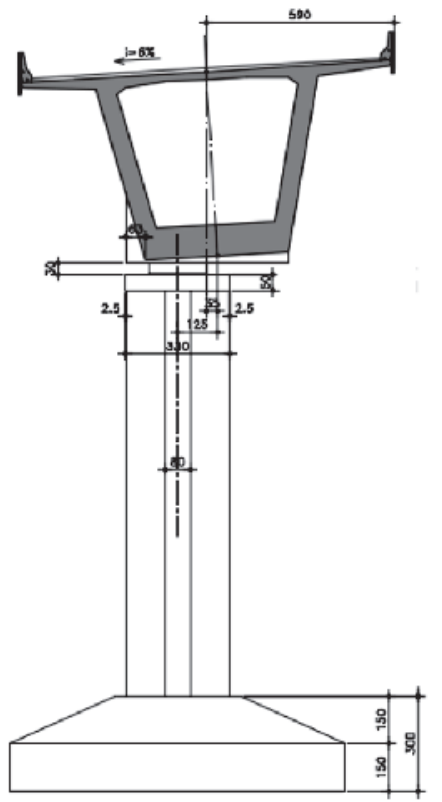

B

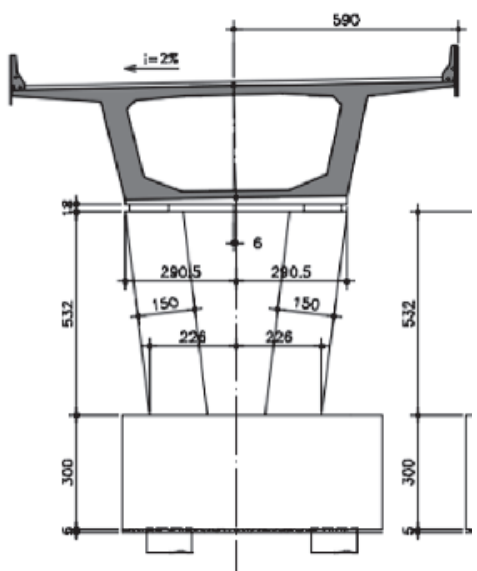

(D)

Figure 4

Cross-sections on pillars: (a) P1 (b) P2 e P3 (c) P4 (d) P5 (drawing supplied by EGT Engenharia)

Table 2

Correlation between the classifications adopted in Brazil (IRI) and by ISO

\begin{tabular}{|c|c|c|}
\hline Pavement condition & $\overline{\boldsymbol{a}}\left(\mathbf{x 1 0}{ }^{-6} \mathbf{m}^{2} /(\mathbf{m} / \mathbf{c i c l o}) \quad\right)$ & IRI (m/km) \\
\hline Excellent & $\bar{\alpha} \leq 0,24$ & $|\mathrm{R}| \leq 1,90$ \\
\hline Excellent to regular & $0,24<\bar{\alpha} \leq 1,00$ & $1,90<|\mathbb{R}| \leq 3,80$ \\
\hline Regular to very bad & $\bar{\alpha}>1,00$ & $\mid \mathrm{RI}>3,80$ \\
\hline
\end{tabular}




\section{Roughness Profile}

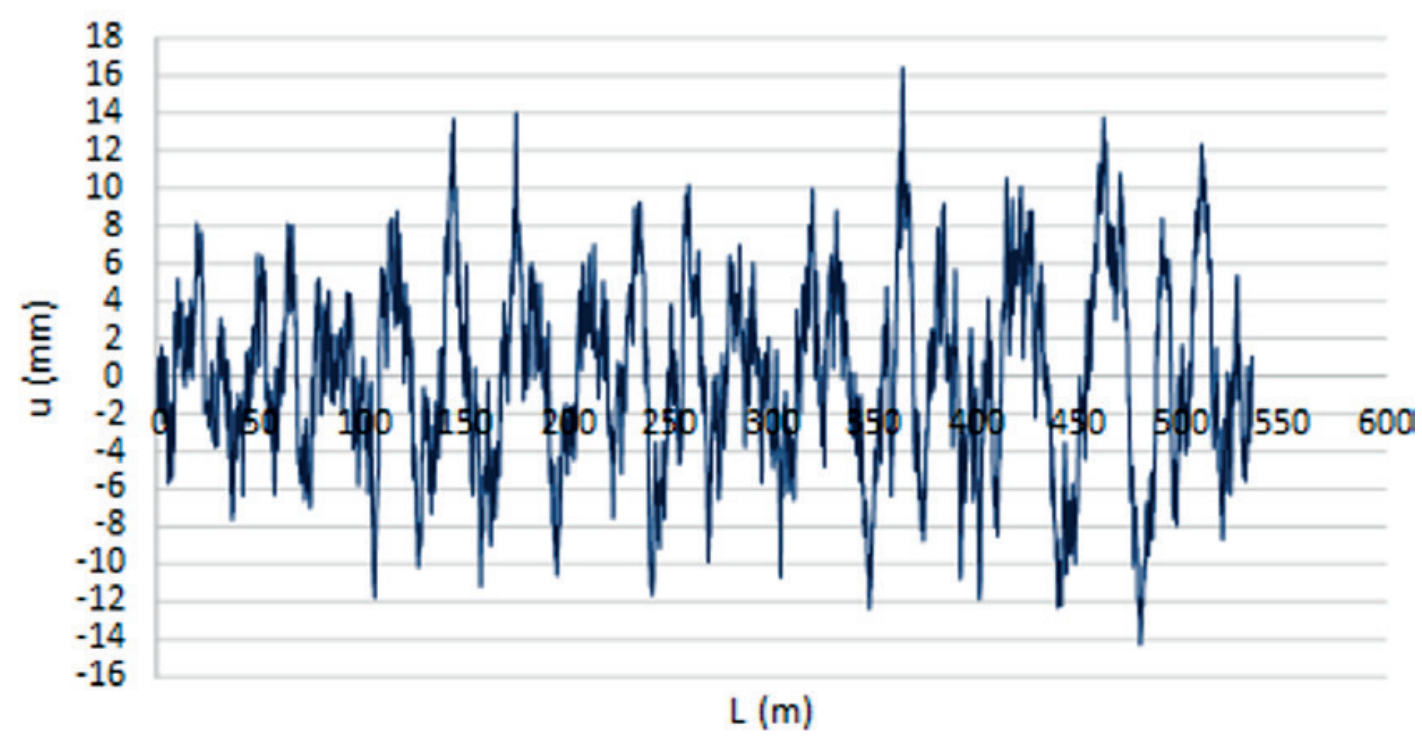

Figure 5

Roughness profile for $|\mathrm{R}|=4,10 \mathrm{~m} / \mathrm{km}, \alpha=1,5 \times 10-6, \beta=1,85$ e $0,5 \mathrm{~m}<\lambda<50 \mathrm{~m}$

The roughness profiles were generated from eq. (1) as a series of cosines (eq. 2) (Santos [1]):

$u_{i r}(x)=\sum_{k=1}^{N} \alpha_{k} \cos \left(2 \pi \omega_{k} x+\varphi_{k}\right)$

where $u_{i r}(x)$ is the random roughness of the pavement; $\alpha_{k}$ is the roughness amplitude; $\omega_{k}$ is the roughness frequency in cycles per meter; $\varphi_{k}$ is the random phase angle defined in the interval $[0.2 \pi]$; $x$ is the position along the bridge axis and $N$ is the total number of terms in the series.

The amplitude $\alpha_{k}$ is expressed by eq. (3):

$\alpha_{k}=2 \sqrt{S_{r}\left(\omega_{k}\right) \Delta \omega}$

Yang and Lin [20] define the frequency increase by $\Delta \omega=\left(\omega_{\max }\right.$ $\left.-\omega_{\min }\right) / N$, where $\omega_{\max }$ and $\omega_{\min }$ are the frequencies of maximum and minimum roughness admitted in the response.

According to Campos [21], the wavelength of the roughness should be between $0.5 \mathrm{~m}$ and $50 \mathrm{~m}$. The waves with dimensions outside these ranges are evaluated as macro-texture, micro-texture and mega-texture, not to be considered as pavement irregularities.

The roughness profile was obtained for an IRI of $4.10 \mathrm{~m} / \mathrm{km}$, which is classified as poor-quality pavement. Figure 5 shows the irregularity profile adopted.

\subsection{Application of the contact forces on the structural model}

The tires iteration efforts are statically condensed in the centre of mass of the vehicle, in order to obtain the vehicle reduced model. Thus, the loading model is reduced to three forces: vertical force $\left(f_{w k}\right)$, due to the bounce movement; transverse moment $\left(m_{v k}\right)$, due to the pitch movement; and longitudinal moment $\left(m_{x k}\right)$, due to the roll movement.

The interaction forces, due to the excitation of the vehicle, condensed statically in its centre of mass, are then applied to the bridge 'unifilar' model. Of course, static loads due to vehicle weight
$(P)$ and centrifugal force $(F C)$ should be added to the interaction efforts. The vehicle is positioned eccentrically with respect to the axis of the bridge, considering the range of its furthest distance, in order to maximize the longitudinal moment (see figure 6a). The forces are then transported to the centre of mass of the cross section, generating a longitudinal moment equal to:

$$
\begin{aligned}
& M_{x k}=F_{c}\left[\left(h+y_{s}\right) \cos \alpha-l \sin \alpha\right]- \\
& P\left[l \cos \alpha+\left(h+y_{s}\right) \sin \alpha\right]+f_{w k} l+m_{x k}
\end{aligned}
$$

where $h$ is the height of the pavement with respect to the centre of the suspended mass, adopted equal to $2.16 \mathrm{~m}, I$ is the eccentricity of the vehicle in relation to the axis of the bridge, equal to $3.15 \mathrm{~m}$, and $y_{s}$ is the distance to the centre of mass of the structure, variable for each cross section.

After calculating the longitudinal moment, the loads are applied to the bridge axis remembering that the interaction forces $f_{w k}$ and $m_{v k}$ must be decomposed according to the super elevation, to take from the vehicle axes $w$ and $v$ to the $Z$ and $Y$ axes of the 'unifilar' model (see figure $6 b$ ). Note that the decomposition of the moment $m_{v k}$ generates a vertical moment $M_{z k}$ which, although small, is considered in the analysis.

Therefore, the vertical force $F_{z k}$ in the global direction of the bridge is shown in eq. 5 :

$F_{z k}=f_{w k} \cos \alpha-P$

The horizontal force from the decomposition of the interaction force must be added to the centrifugal inertia force, resulting in the total horizontal force $F_{y k}$ to be applied in the bridge model (eq. 6).

$F_{y k}=f_{w k} \sin \alpha-F_{c}$

The moment $m_{v k}$ must also be decomposed at a moment in the $Y$ direction and a moment in the $Z$ direction (eq. 7 ).

$M_{z k}=-m_{v k} \sin \alpha$

It was considered that the applied moment $M_{y k}$ is equal to the 


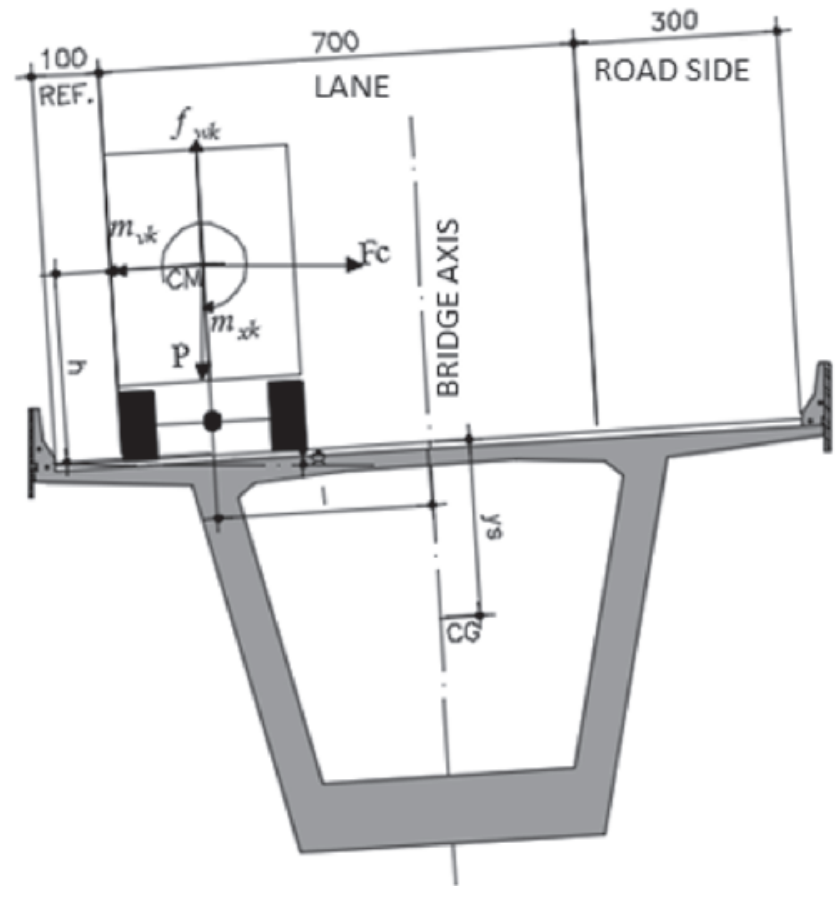

A

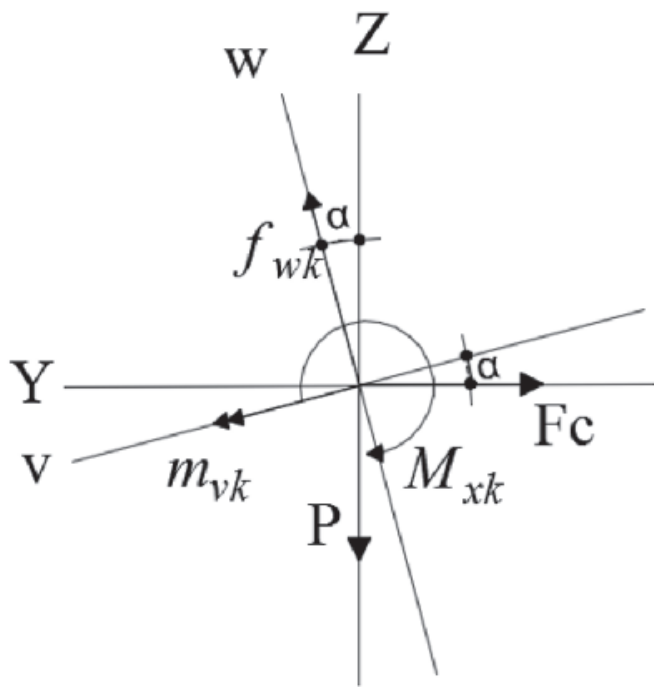

B

\section{Figure 6}

(a) Positioning of the vehicle to calculate the forces. (b) Decomposition of the forces, according to super elevation

decomposed moment of interaction $m_{y k}$ plus the moment due to the distribution of the vehicle's own weight (eq. 8).

$M_{y k}=\left[\begin{array}{c}m_{v k}+\left(P_{1}+P_{4}\right) d_{1} \cos \alpha- \\ \left(P_{2}+P_{5}\right) d_{2} \cos \alpha-\left(P_{3}+P_{6}\right) d_{3} \cos \alpha\end{array}\right] \cos \alpha$

where $P_{i}$ is the force that the wheel $i$ exerts on the structure due to the dead weight of the vehicle.

These forces are applied to the 'unifilar' bridge model, divided into three-dimensional beam elements, so that at each node $k$ of the discretized bridge the five reduced forces are specified, i.e., vertical force $\left(F_{z k}\right)$, transverse moment $\left(M_{y k}\right)$, longitudinal moment $\left(M_{x k}\right)$, vertical moment $\left(M_{z k}\right)$ and horizontal force $\left(F_{y k}\right)$, see figure 7 . Thus, at the instant the vehicle is on node $k$, the five reduced forces are specified and, for the other instants, these values are null, because the centre of mass of the vehicle is on other nodes.

\section{Results and discussions}

First of all, the modal analyses of the bridge and the vehicle, whose frequencies are found in table 3 , were performed. From the first two vibration modes of the bridge, the Rayleigh coefficients for $2.5 \%$ modal damping $\xi$ were calibrated.

The bridge has very low frequencies, as seen in table 3 . In this way, the higher the speed, the closer to the frequency of the bridge will be the loading of the vehicle. Thus, the study was carried out for the maximum speed for the traffic conditions in the bridge of 80 $\mathrm{km} / \mathrm{h}$, as well as for speeds of $60 \mathrm{~km} / \mathrm{h}$ and $40 \mathrm{~km} / \mathrm{h}$.

Firstly, the efforts of the vehicle-pavement interaction were obtained, under the initially adopted hypothesis of rigid deck. These efforts were decomposed according to the super elevation of the bridge, also considering the moments of transportation to the centre of mass of the section of the bridge.
With the applied efforts in the model of the bridge the dynamic analysis was carried out, resulting in temporal displacement functions for each node. As the applied forces were obtained considering rigid deck, they need to be adjusted, since the bridge has displacements when the vehicle travels along the bridge. This adjustment is performed through the iterative process described below:

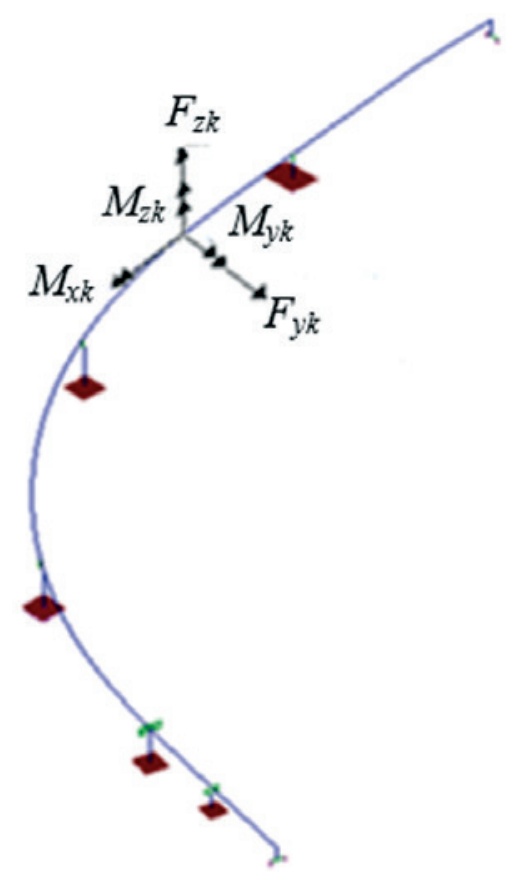

Figure 7

'Unifilar' model of the curved bridge with an example of the applied forces at the nodes 
Table 3

Bridge and vehicle natural frequencies

\begin{tabular}{|c|c|c|c|c|}
\hline Modes & $\begin{array}{c}\text { Bridge frequencies } \\
\mathbf{( H z})\end{array}$ & Bridge mode & $\begin{array}{c}\text { Vehicle frequency } \\
\mathbf{( H z})\end{array}$ & Car mode \\
\hline 1 & 0,47 & Vertical bending & 1,68 & $\begin{array}{c}\text { Bounce of the } \\
\text { suspended mass }\end{array}$ \\
\hline 2 & 0,59 & $\begin{array}{c}\text { Torsion with } \\
\text { longitudinal } \\
\text { displacement }\end{array}$ & 2,15 & $\begin{array}{c}\text { Roll of the suspended } \\
\text { mass }\end{array}$ \\
\hline 3 & 0,62 & $\begin{array}{c}\text { Lateral bending of } \\
\text { the straight span }\end{array}$ & 2,23 & $\begin{array}{c}\text { Pitch of the } \\
\text { suspended mass }\end{array}$ \\
\hline 4 & 0,69 & $\begin{array}{c}\text { Vertical bending } \\
\text { Roll of the non- } \\
\text { suspended mass }\end{array}$ \\
\hline 5 & 0,89 & $\begin{array}{c}\text { Lateral bending } \\
\text { with torsion }\end{array}$ & 10,06 & $\begin{array}{c}\text { Pitch of the non- } \\
\text { suspended mass }\end{array}$ \\
\hline 6 & 0,92 & $\begin{array}{c}\text { Lateral bending } \\
\text { with torsion }\end{array}$ & 10,14 & $\begin{array}{c}\text { Roll of the non- } \\
\text { suspended mass }\end{array}$ \\
\hline
\end{tabular}

$1^{\text {st }}$ Step: From the hypothesis of rigid deck and undeformed structure, for each instant $t$, the pavement roughness $u_{r}\left(x_{i}\right)$ is applied to each wheel $i$ of position $x_{i}=x-d, x$ being the position of the centre of mass (CM) of the vehicle at time $t(x=V . t)$ and $d$ the longitudinal distance from the $\mathrm{CM}$ to the tire (see figure 8 ). By the dynamic analysis of the vehicle, the contact forces for each wheel $f_{1}(t)$ to $f_{6}(t)$ are obtained.

$2^{\text {nd }}$ Step: Reduction of the forces into the centre of the suspended mass for application in the 'unifilar' structural model.

Note that when the CM is at the beginning of the bridge $(x=0)$ only the first wheel axle is on the bridge and is influenced by the irregularity. The other axes, which would be outside the bridge, despite being considered because of the reduction of the forces in the vehicle centre of mass, are not subjected to any irregularity, and, therefore, would not influence the dynamic response.

$3^{\text {rd }}$ Step: Application of the forces on the model of the bridge.

$4^{\text {th }}$ Step: Evaluation of the structural displacement, namely the vertical translation $\left(u_{z k, j}(t)\right)$, longitudinal rotation $\left(\theta_{x k, j}(t)\right)$ and transversal rotation $\theta_{y k, j}(t)$, for each node $k$, at the time $t$ in which the vehicle centre of mass $(\mathrm{CM})$ is on it.

It is known that a displacement should be extracted for each wheel. However, due to the application of the reduced efforts, in this methodology a simplification was adopted, obtaining only the displacements and rotations for the centre of mass of the vehicle. The re-

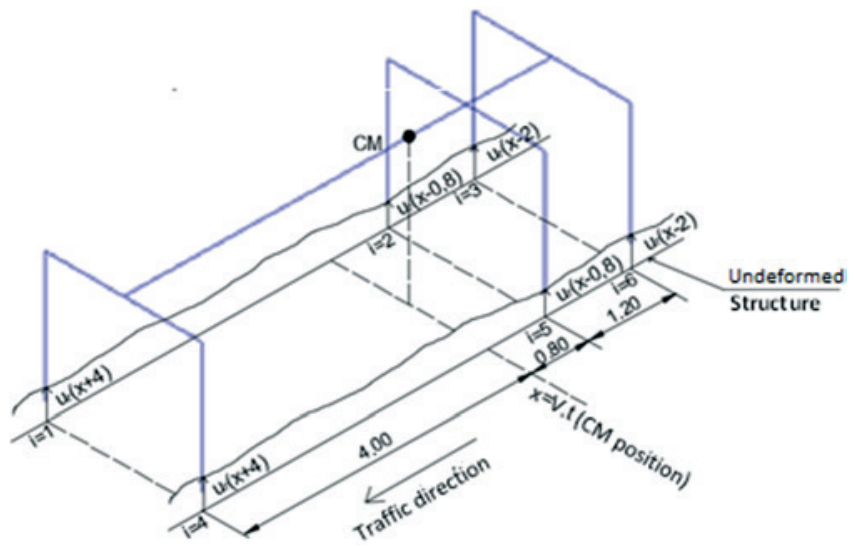

Figure 8

Application of the irregularity on the vehicle model spective displacements for each wheel can be found by multiplying the longitudinal and transverse rotations by the corresponding distances from the centre of mass to each wheel, adding these parcels to the vertical displacements, as will be seen in the next step. $5^{\text {th }}$ Step: The displacements obtained in the first iteration $j=1$ are added to the roughness of the pavement $u_{r}\left(x_{i}\right)$ considered in the first step, for each wheel $i$ and for each time $t$, in order to obtain an "equivalent irregularity" function, considering the effects of structural displacements distinctly on each tire line (see equation 9).

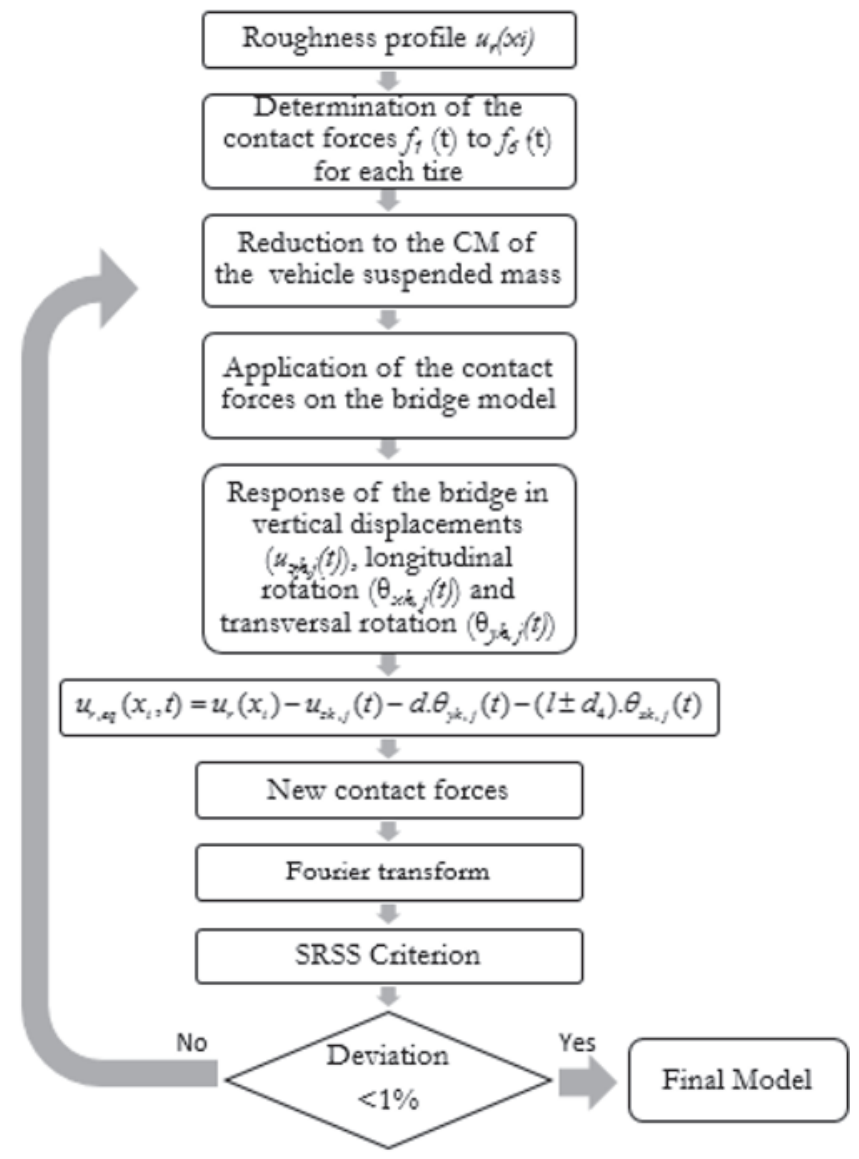

Figure 9

Flowchart of the proposed methodology 

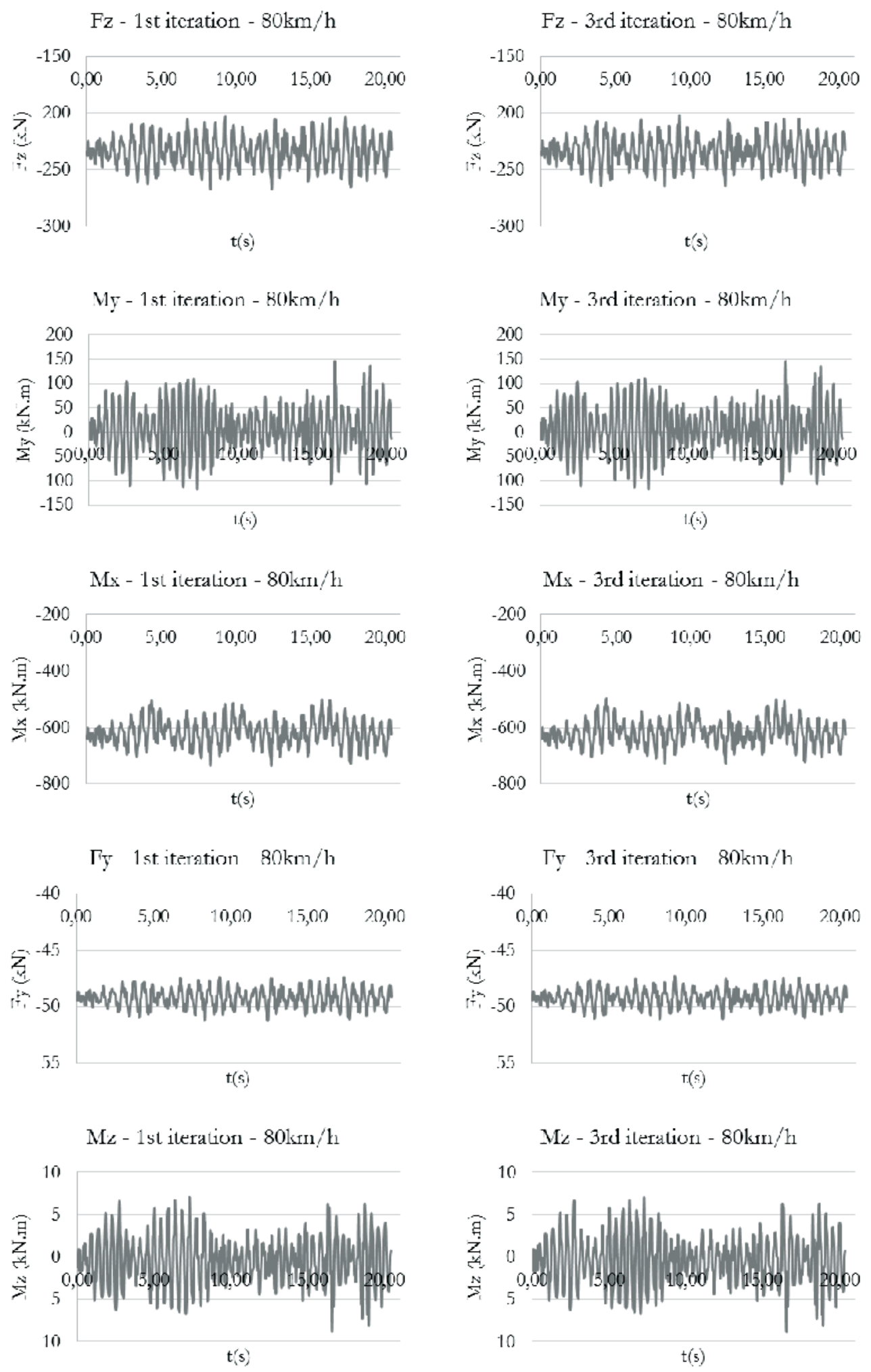

\section{Figure 10}

Comparison of the efforts applied to the bridge in the 1st iteration (rigid deck) and 3rd iteration with velocity of $80 \mathrm{~km} / \mathrm{h}$ 

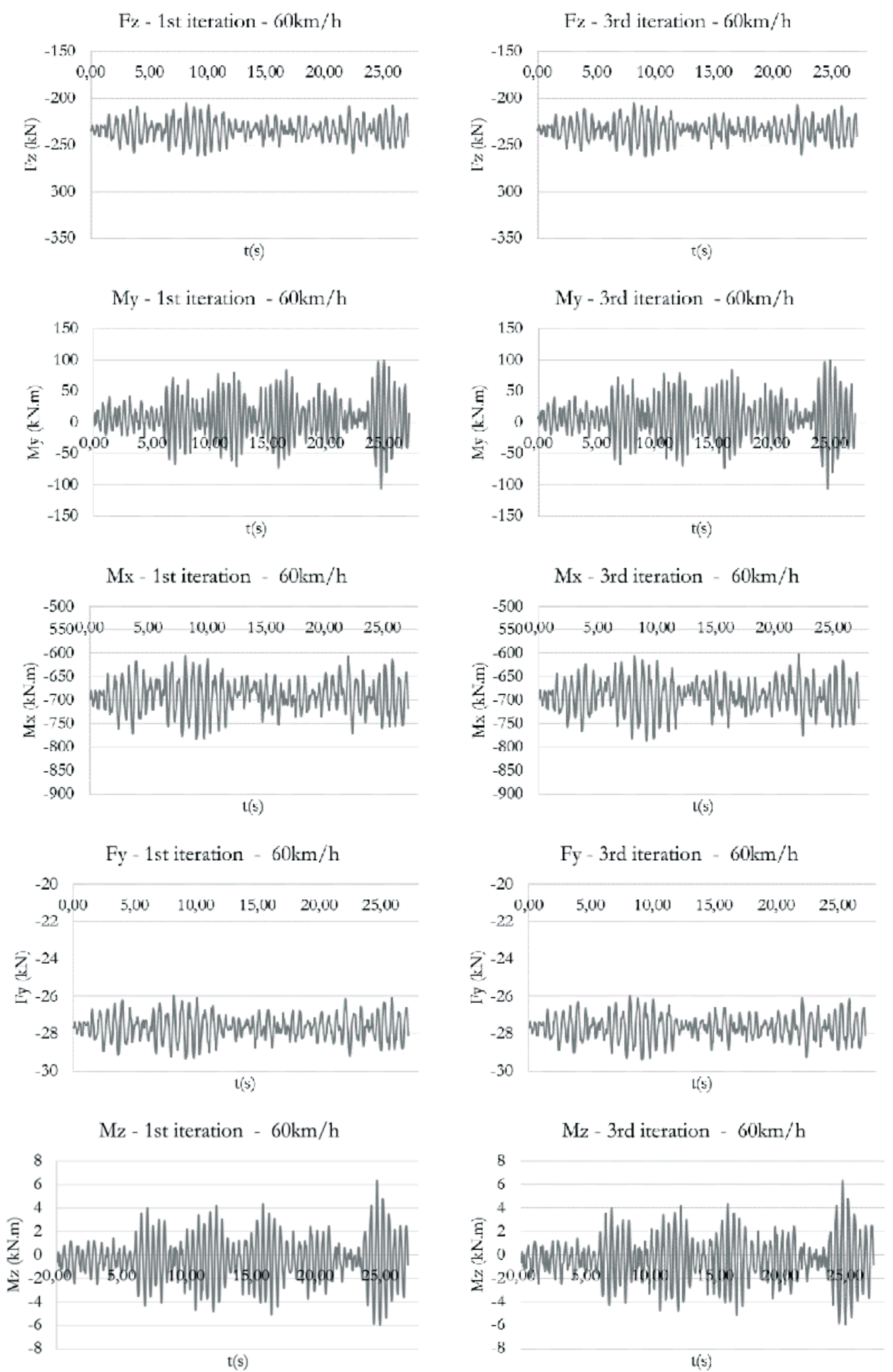

\section{Figure 11}

Comparison of the efforts applied to the bridge in the 1st iteration (rigid deck) and 3rd iteration with velocity of $60 \mathrm{~km} / \mathrm{h}$ 


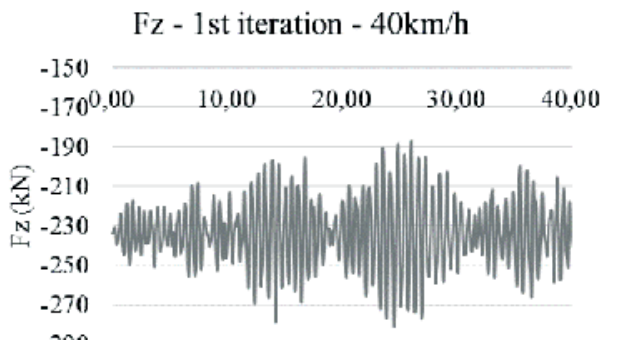

$t(s)$

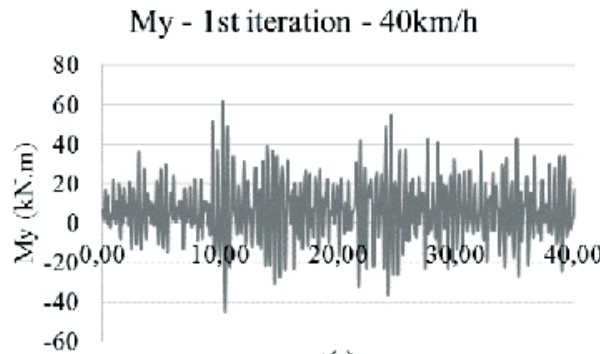

$\mathrm{t}(\mathrm{s})$
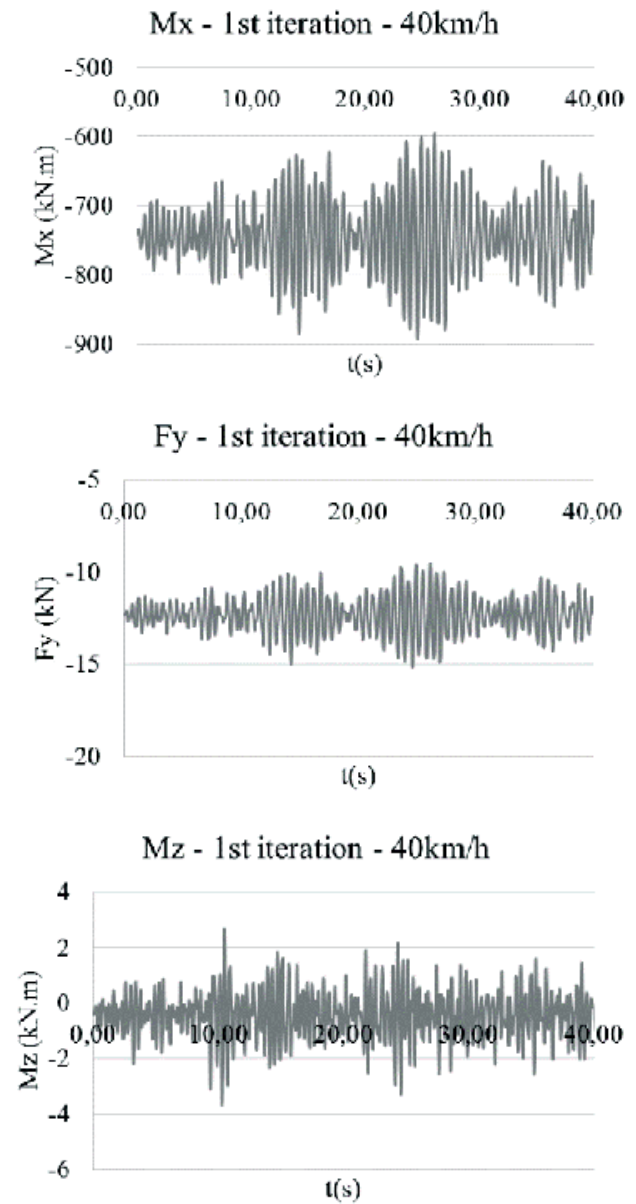

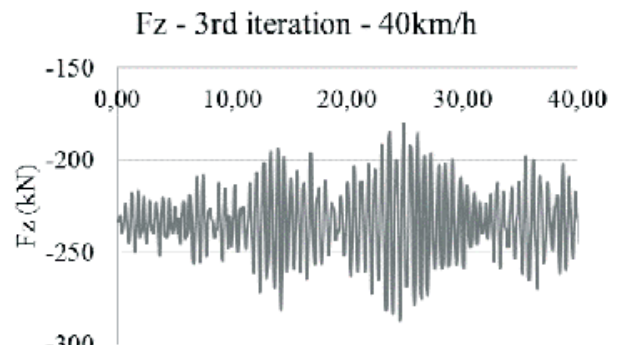

$t(s)$

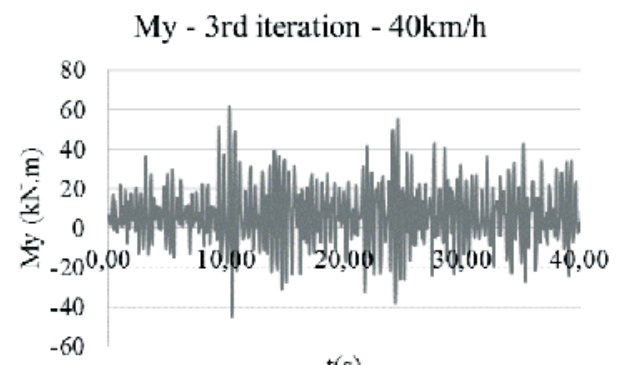

$\mathrm{t}(\mathrm{s})$
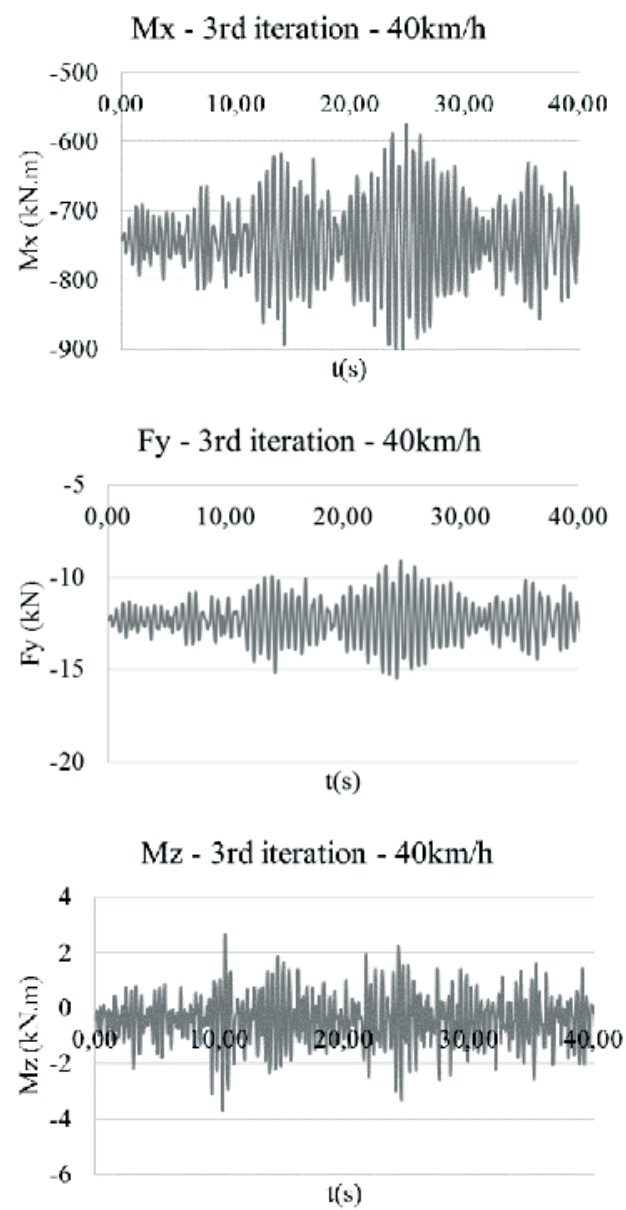

\section{Figure 12}

Comparison of the efforts applied to the bridge in the 1st iteration (rigid deck) and 3rd iteration with velocity of $40 \mathrm{~km} / \mathrm{h}$ 
$u_{r, e q}\left(x_{i}, t\right)=u_{r}\left(x_{i}\right)-u_{z k, j}(t)-d_{.} \theta_{y k, j}(t)-\left(l \pm d_{4}\right) \theta_{x k, j}(t)$

where $/$ is the distance from the bridge axis to the vehicle axis.

$6^{\text {th }}$ Step: New contact forces are obtained by the dynamic analysis of the vehicle, under the support excitation provided by the "equivalent irregularity" of the $3^{\text {rd }}$ step. $7^{\text {th }}$ Step: After the new contact forces are obtained, the responses of the interaction forces in the frequency domain are determined by applying the Fourier transform to each iteration.

$8^{\text {th }}$ Step: The deviations between the result in the frequency domain of iteration $i$ and iteration $i-1$ are calculated using the SRSS criterion - Square Root of the Sum of Squares for the maximum amplitudes. $9^{\text {th }}$ Step: If the deviation between two consecutive iterations is less than

Tourier 1 st iteration $\mathrm{v}=80 \mathrm{~km} / \mathrm{h}$

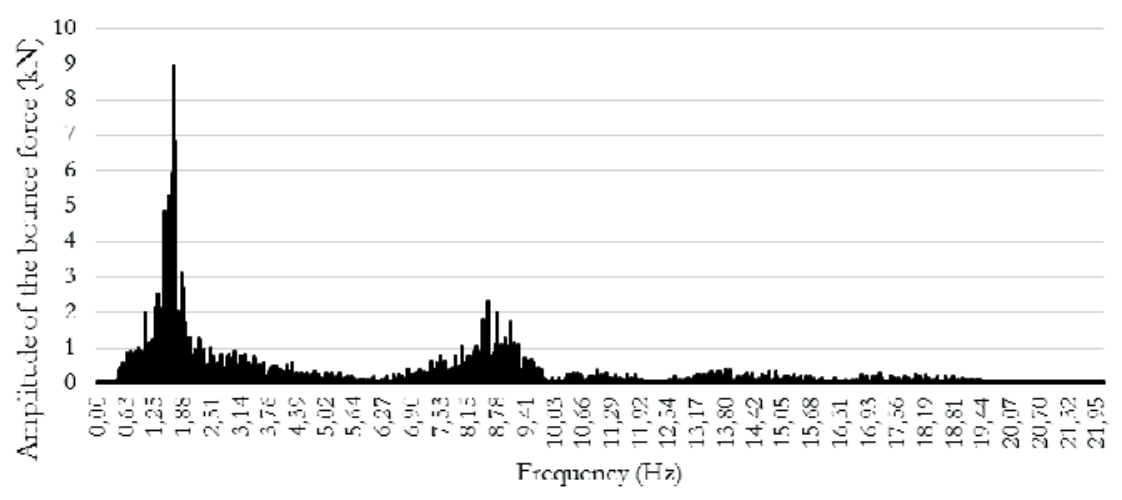

Fonrier 2nd iteration $\mathrm{v}^{-80 \mathrm{~km} / \mathrm{h}}$

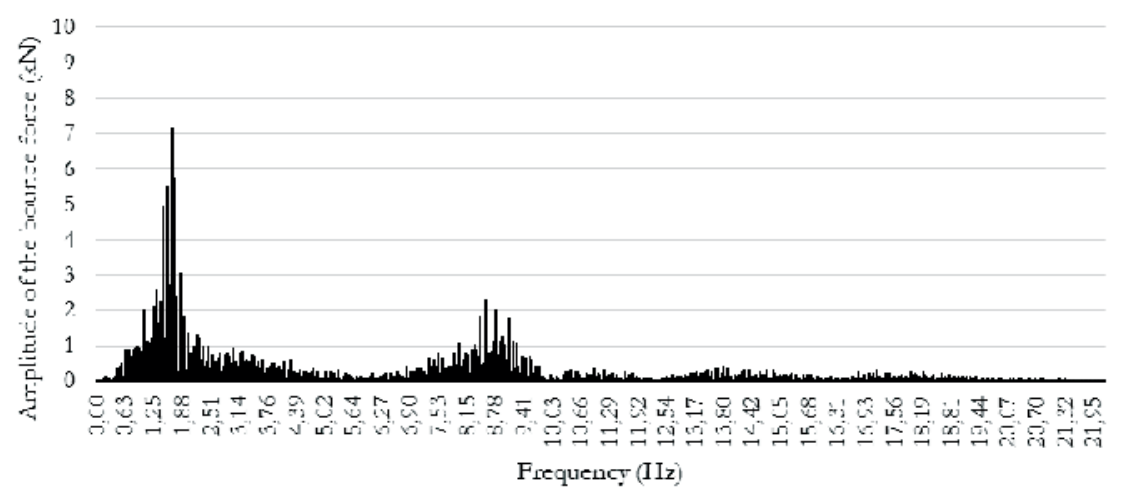

Fourier 3rd iteration $\mathrm{v}-80 \mathrm{~km} / \mathrm{h}$

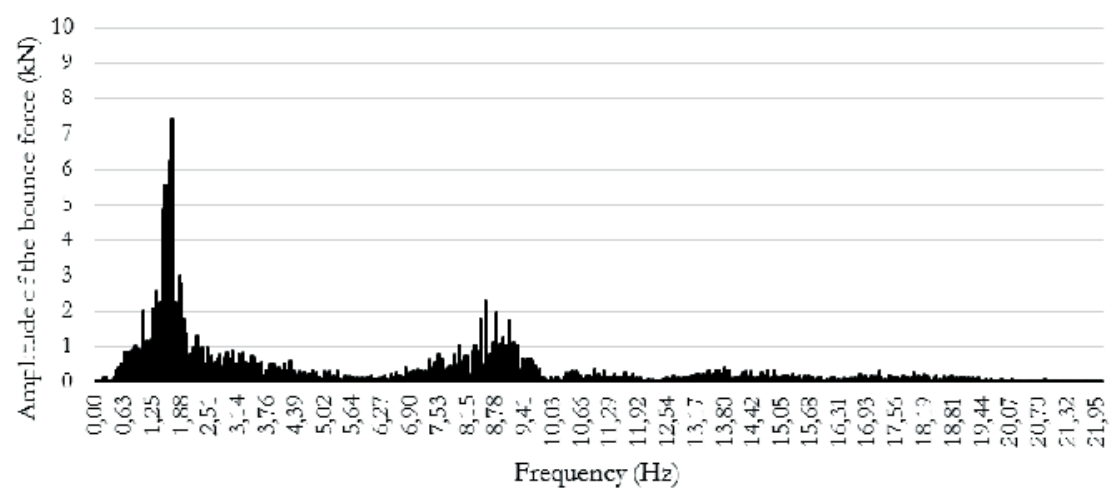

Figure 13

Fourier analysis of bounce forces $F_{z^{\prime}}$ for the three iterations $-V=80 \mathrm{~km} / \mathrm{h}$ 
$1 \%$, then it is considered that convergence has been obtained and the final model analysis is performed. If not, steps 2 through 6 should be repeated until convergence of the interaction forces are obtained. Figure 9 shows a flowchart with the proposed methodology. In this study, only three iterations were necessary to obtain the convergence of the interaction forces, except for the speed of $60 \mathrm{~km} / \mathrm{h}$ for which only two iterations would be sufficient. Figures 10 to 12 show the comparison of the forces applied to the bridge for the first and third iterations. It was obtained the Fourier transform of the interaction force $F_{z}$, referring to the bounce motion, for each iteration, evaluating the deviation between the result of the iteration $i$ and the iteration $i-1$, using the SRSS criterion - Square Root of the Sum of

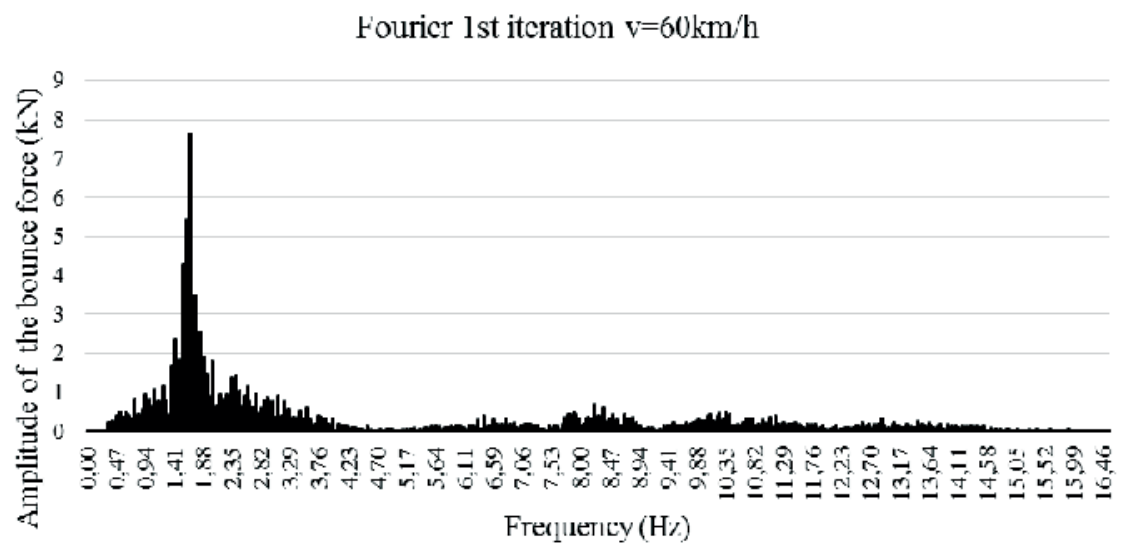

Fourier 2nd iteration v $60 \mathrm{~km} / \mathrm{h}$

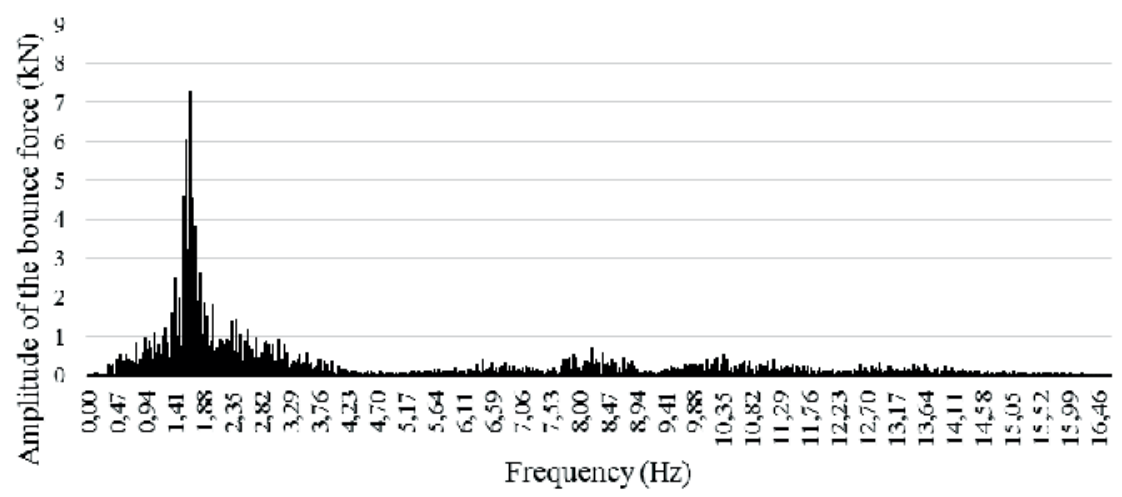

Fourier $3 \mathrm{rd}$ iteration v $60 \mathrm{~km} / \mathrm{h}$

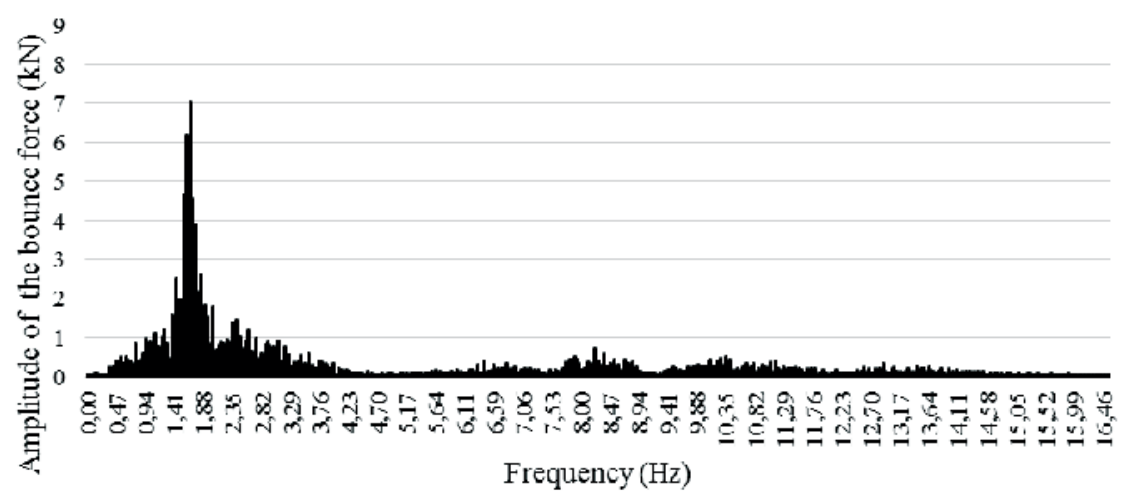

Figure 14

Fourier analysis of bounce forces $F_{z^{\prime}}$ for the three iterations $-V=60 \mathrm{~km} / \mathrm{h}$ 
Squares for the maximum amplitudes, as indicated in eq. 10:

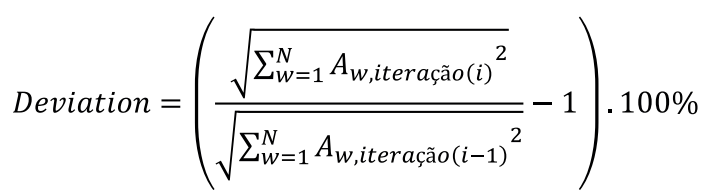

where $n$ is the number of frequencies considered for the calculation of the amplitudes

Figures 13 to 15 show the Fourier analyses for each interaction.

(10) Note that, for all iterations, the highest amplitude peak has a frequency corresponding to $1.67 \mathrm{~Hz}$, very close to $1.68 \mathrm{~Hz}$ of the first bounce mode of the vehicle's suspended mass. It is also noticed

Fouricr lst iteration $\mathrm{v}=40 \mathrm{~km} / \mathrm{h}$

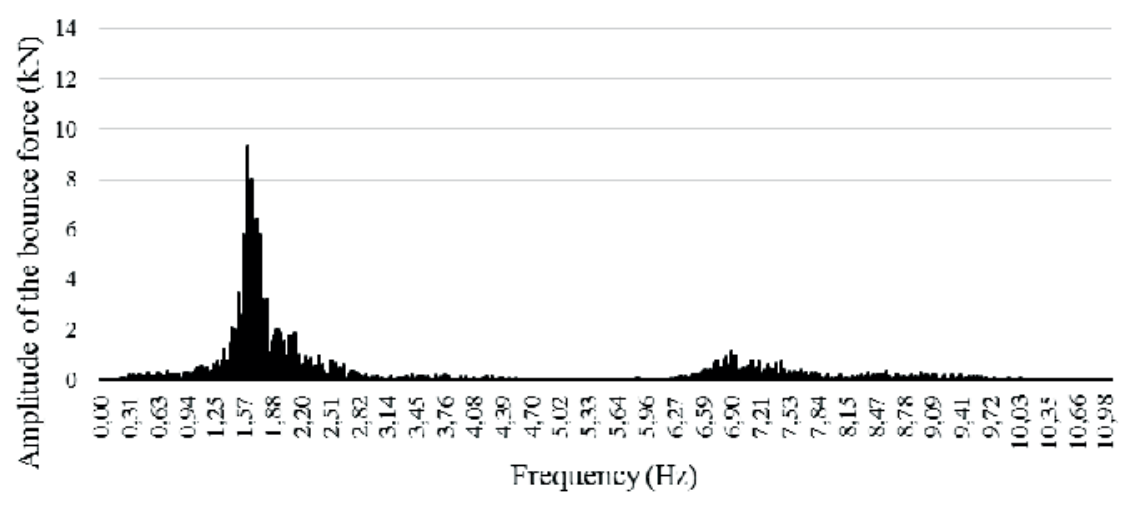

Fourier 2nd iteration v $40 \mathrm{~km} / \mathrm{h}$

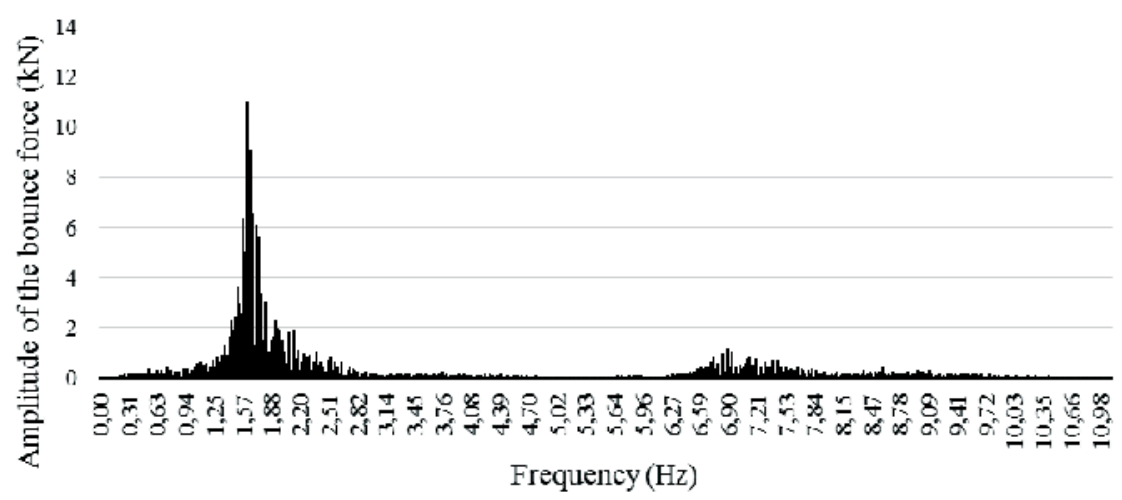

Fourier $3 \mathrm{rd}$ iteration v $40 \mathrm{~km} / \mathrm{h}$

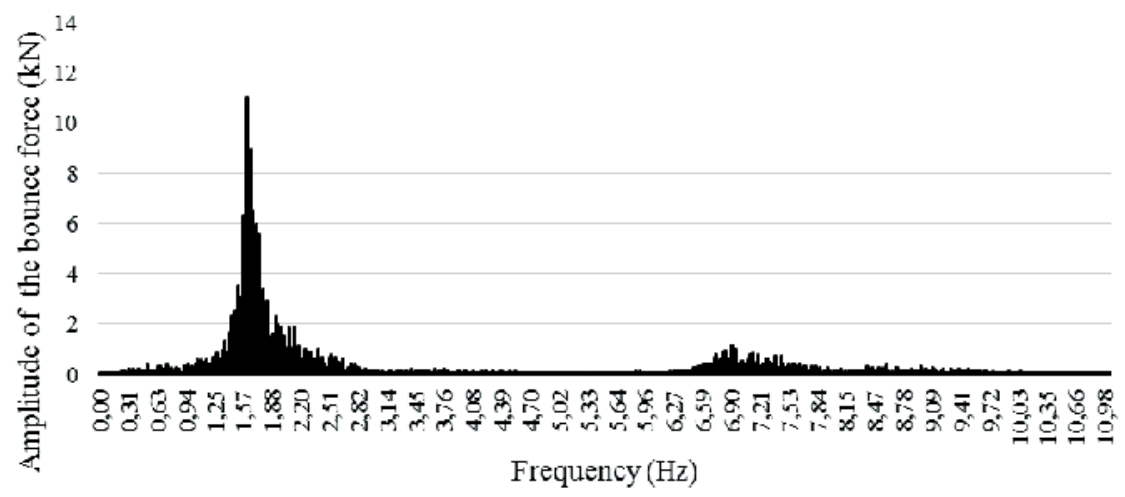

Figure 15

Fourier analysis of bounce forces $F_{z^{\prime}}$ for the three iterations - V $=40 \mathrm{~km} / \mathrm{h}$ 


\section{Table 4}

Difference between the iterations using the SRSS method

\begin{tabular}{|c|c|c|}
\hline Velocity & Iteration & Deviation (\%) \\
\hline \multirow{4}{*}{80} & $1-2$ & $-3,60$ \\
\cline { 2 - 3 } & $2-3$ & $-0,10$ \\
\cline { 2 - 3 } & $1-3$ & $-3,70$ \\
\hline \multirow{3}{*}{60} & $1-2$ & 0,34 \\
\cline { 2 - 3 } & $2-3$ & $-0,20$ \\
\cline { 2 - 3 } & $1-3$ & 0,14 \\
\hline \multirow{4}{*}{40} & $1-2$ & 8,5 \\
\cline { 2 - 3 } & $2-3$ & $-0,03$ \\
\cline { 2 - 3 } & $1-3$ & 8,47 \\
\hline
\end{tabular}

that there is an increase in the amplitudes near the frequencies of 8 to $10 \mathrm{~Hz}$, which are close to the vibration modes of the non-suspended masses of the vehicle, but with much smaller amplitudes. Table 4 shows the differences found between the iterations. From the static point of view, one would expect that the rigid deck situation would correspond to larger contact forces and then, with the correction of the displacements, the flexibilization of the deck would decrease the interaction forces. However, this didn't occur in a general way in the dynamic analysis. Depending on the frequency that is excited, the flexibilization of the deck can increase or decrease the interaction forces. As seen in Table 4 , for the velocities of $40 \mathrm{~km} / \mathrm{h}$ and $60 \mathrm{~km} / \mathrm{h}$, the interaction forces increased from the first to the last iteration, whereas for the velocity of $80 \mathrm{~km} / \mathrm{h}$ the interaction forces were reduced.

Table 5 presents the displacements and positive bending moments for the $1^{\text {st }}$ and $3^{\text {rd }}$ iterations for the speeds of $80 \mathrm{~km} / \mathrm{h}, 60 \mathrm{~km} / \mathrm{h}$ and
$40 \mathrm{~km} / \mathrm{h}$. A good convergence is observed, with small difference of the results of bending moments, and the structural displacements practically did not change.

For the purpose of illustration, figures 16 and 17 present the history of displacements and bending moments in the four curved spans, where one can observe the proximity of the answers between the $1^{\text {st }}$ and $3^{\text {rd }}$ iterations.

\section{Conclusions}

The most important product of this work is the proposition of a simplified methodology for the dynamic analysis of curved bridges, in which the separation of bridge and vehicle models is postulated, and these are coupled only by the interaction forces. For the determination of these forces it is considered that the vehicle is initially on a rigid deck and, later, this hypothesis is corrected, through an iterative process. This methodology is both simple and accessible to structural engineers, using a commercially available finite element program. Thus, designers will be increasingly able to perform dynamic analyses on curved bridges, simultaneously considering the effect of moving loads constituted by centrifugal forces and vehicle-pavement interaction forces, and using more realistic models that consider the data referring to the actual traffic in the road networks, as well as the state of conservation of the pavements. In the case study addressed herewith, no more than three iterations were necessary to obtain convergence of the interaction forces. It was observed that, depending on the frequency being excited, the interaction forces may increase or decrease with the flexibility correction, differently to what is expected under purely static reasoning, according to which the more rigid the deck, the larger the load it would absorb.

It was also observed a good convergence in the dynamic responses of the bridge, with small difference of the bending moments

\section{Table 5}

Displacements and positive bending moments $-1^{\text {st }}$ and $3^{\text {rd }}$ iteration

\begin{tabular}{|c|c|c|c|c|c|}
\hline \multirow{3}{*}{ Velocity } & \multirow{2}{*}{ Local } & \multicolumn{2}{|c|}{$\mathbf{1}^{\text {st iteration }}$} & \multicolumn{2}{c|}{ 3rd iteration } \\
\cline { 2 - 6 } & $\begin{array}{c}\text { Displacement } \\
\text { (cm) }\end{array}$ & $\begin{array}{c}\text { Positive bending } \\
\text { moment }(\mathbf{k N m})\end{array}$ & $\begin{array}{c}\text { Displacement } \\
\text { (cm) }\end{array}$ & $\begin{array}{c}\text { Positive bending } \\
\text { moment (kNm) }\end{array}$ \\
\hline \multirow{4}{*}{$40 \mathrm{~km} / \mathrm{h}$} & 1 st span & 1,01 & 4429,65 & 1,02 & 4609,40 \\
\cline { 2 - 6 } & 2nd span & 1,32 & 4459,04 & 1,32 & 4565,55 \\
\cline { 2 - 6 } & 3rd span & 1,36 & 4574,83 & 1,36 & 4781,33 \\
\cline { 2 - 6 } & 4th span & 0,98 & 4760,27 & 0,98 & 4776,20 \\
\hline \multirow{4}{*}{$60 \mathrm{~km} / \mathrm{h}$} & 1st span & 0,99 & 4428,30 & 0,99 & 4589,45 \\
\cline { 2 - 6 } & 2nd span & 1,30 & 4361,08 & 1,30 & 4478,83 \\
\cline { 2 - 6 } & 3rd span & 1,35 & 4660,32 & 1,35 & 4656,25 \\
\cline { 2 - 6 } & 4th span & 0,96 & 4693,66 & 0,96 & 4694,49 \\
\hline \multirow{4}{*}{$80 \mathrm{~km} / \mathrm{h}$} & 1st span & 1,01 & 4720,57 & 1,01 & 4691,20 \\
\cline { 2 - 6 } & 2nd span & 1,33 & 4681,77 & 1,33 & 4545,50 \\
\cline { 2 - 6 } & 3rd span & 1,34 & 4758,53 & 1,34 & 4673,27 \\
\cline { 2 - 6 } & & 0,94 & 4676,79 & 0,94 & 4673,47 \\
\hline
\end{tabular}



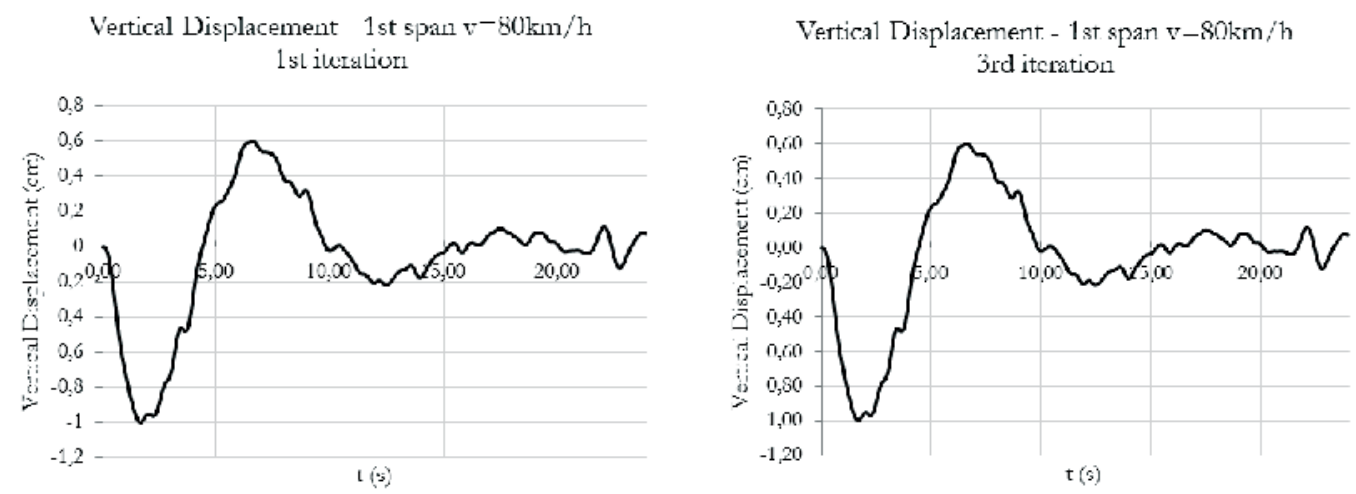

Vertical 1 isplacement. 2nd span $\mathrm{v}-80 \mathrm{~km} / \mathrm{h}$

1st itcration

Vertical Displacement 2nd span v-80 $\mathrm{km} / \mathrm{h}$ 3rditeration
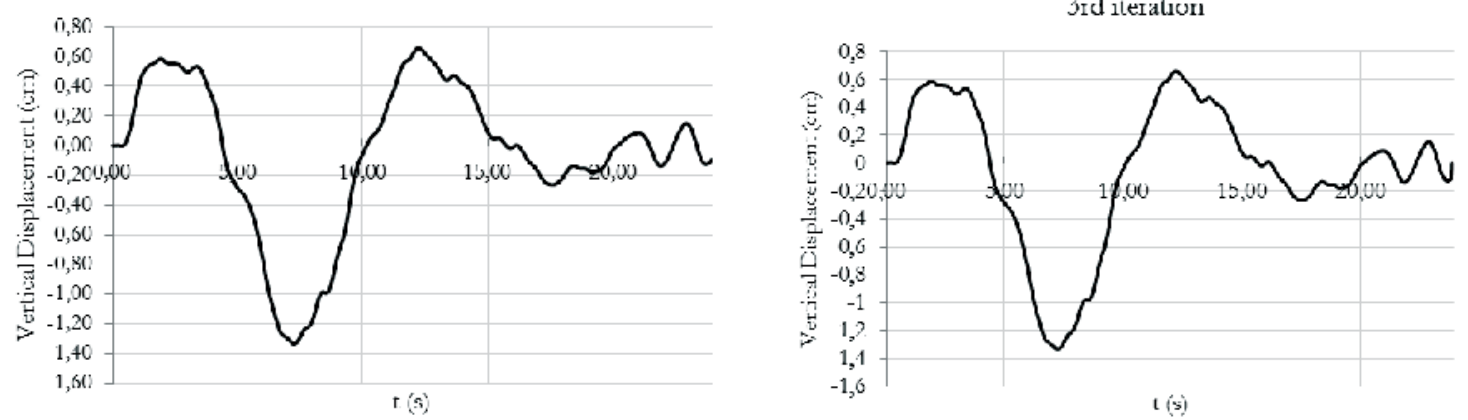

Vertical Dislplacement - 3rd span v $=80 \mathrm{~km} / \mathrm{h}$ 3rd iteration
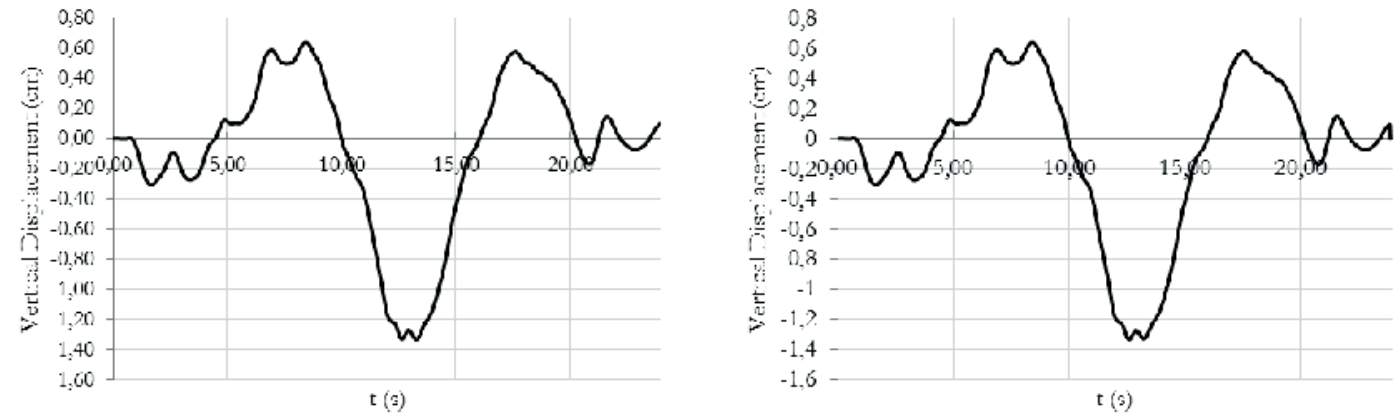

Vertical Tisplacement 4 th span $\bar{v}-80 \mathrm{~km} / \mathrm{h}$ 1st span

Deslocamento vertical $4^{\circ}$ vảo $\mathrm{v}-80 \mathrm{~km} / \mathrm{h}$ $3^{\mu}$ iteraçầo
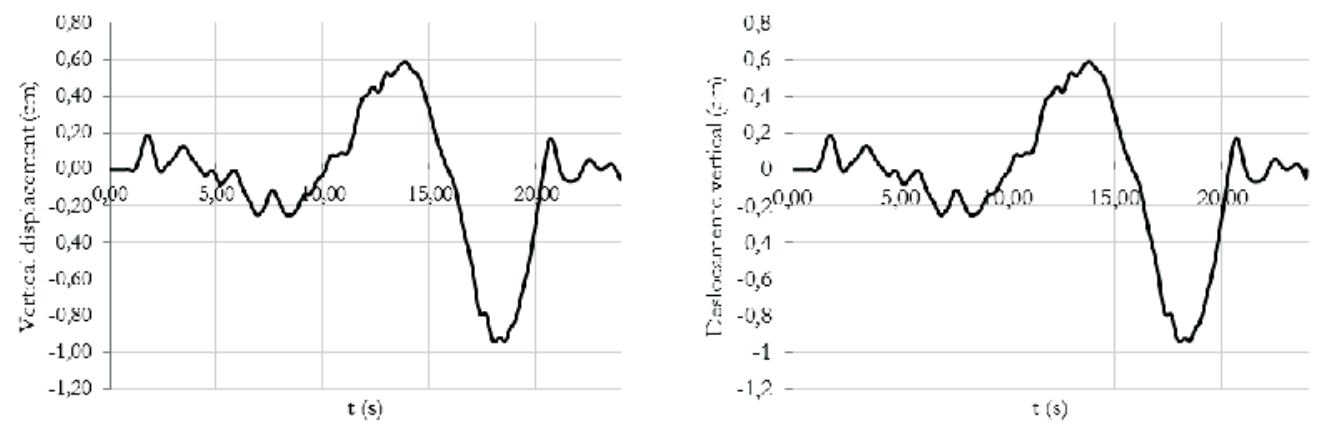

Figure 16

Comparison of displacements between the $1^{\text {st }}$ and $3^{\text {rd }}$ iterations $-V=80 \mathrm{~km} / \mathrm{h}$ 
between the first and third iteration, and the structural displacements practically did not change.

It is worth emphasizing that the results presented here are completely dependent of the structural typology and its dynamic characteristics, and may present considerable differences if some of these factors are altered. However, the proposed methodology

Positive Bending Moment My- Ist span - v=80km $/ \mathrm{h}$ lst iteration

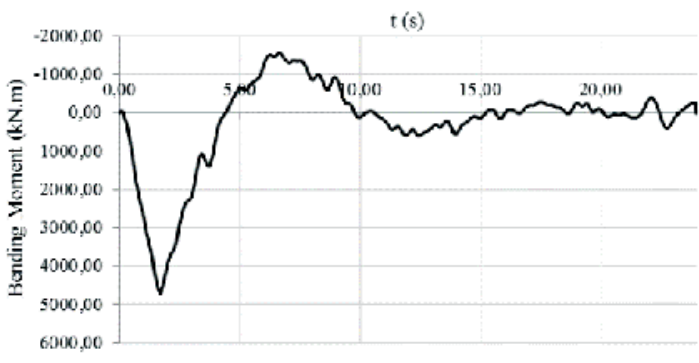

Positive Bending Moment My - 2nd span - $\mathrm{v}-80 \mathrm{~km} / \mathrm{h}$ 1st iteration

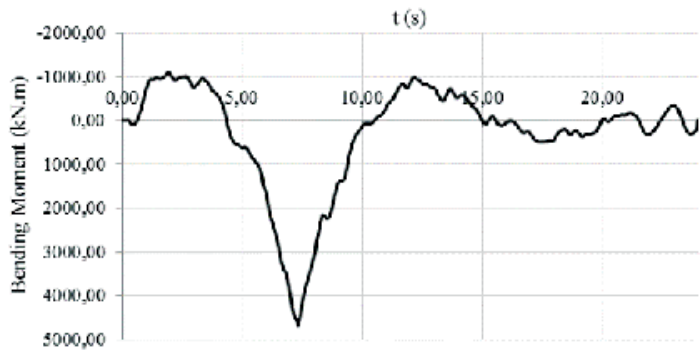

Positive Bending Moment My- 3rd span - v=80km $/ \mathrm{h}$ 1st iteration

$t(s)$

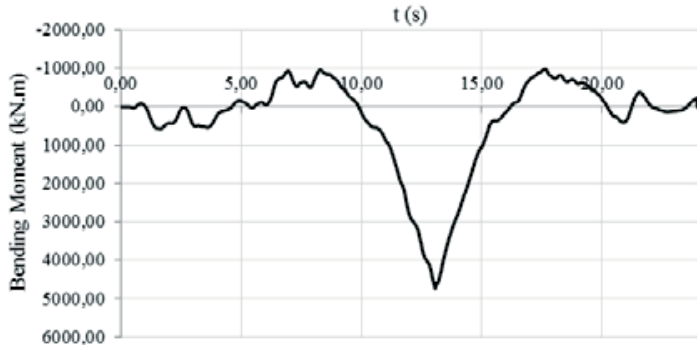

Positive Bending Moment My - 4th span - $-80 \mathrm{~km} / \mathrm{h}$ 1st iteration

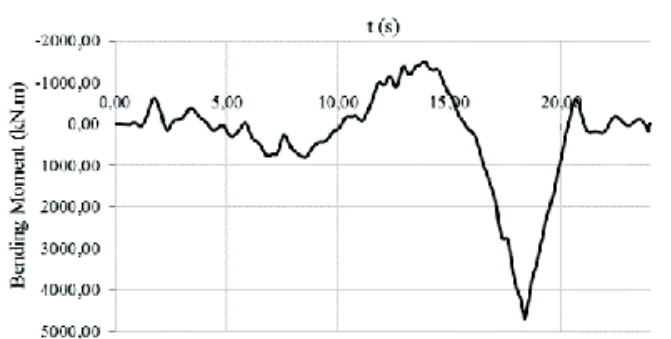

and the iterative procedure through simple adaptations remain an adequate means to evaluate the structural dynamic response.

\section{Acknowledgments}

The authors thank EGT Engenharia for supplying the 900 branch de-

Positive Bending Moment My- Ist span - v= $80 \mathrm{~km} / \mathrm{h}$ 3rd iteration

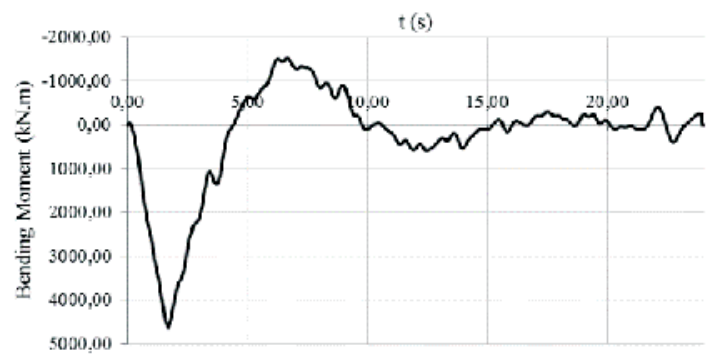

Positive Beding Moment My - 2nd span - v $=80 \mathrm{~km} / \mathrm{h}$ 3rd iteration

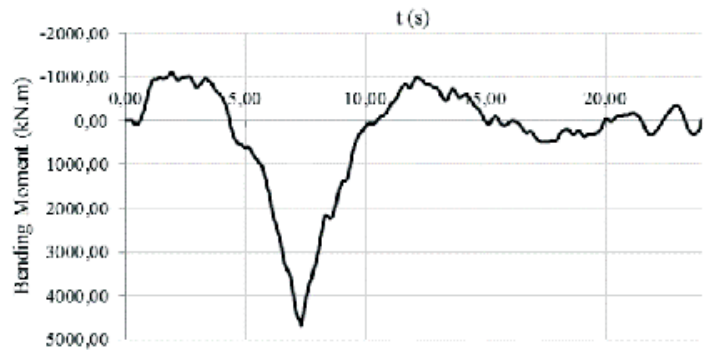

Positive Benidng Moment My - 3rd span - v $-80 \mathrm{~km} / \mathrm{h}$ 3rd iteration

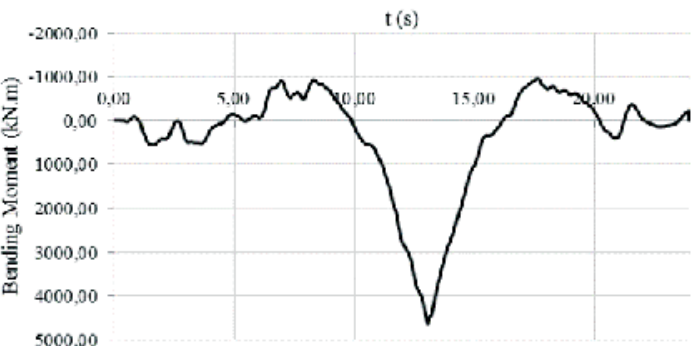

Positive Bending Moment My -4 th span $-\mathrm{v}=80 \mathrm{~km} / \mathrm{h}$ 3rd iteration

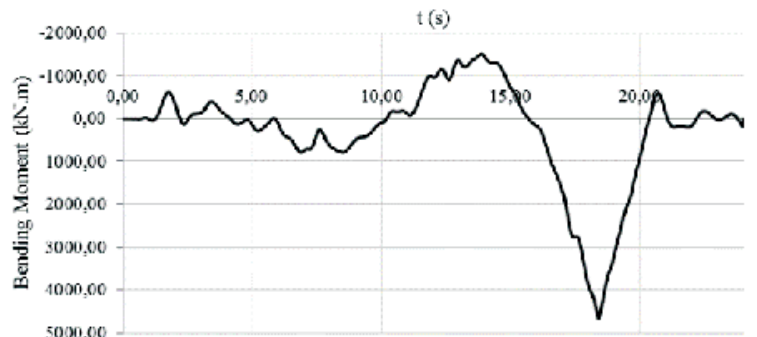

5090,00

Figure 17

Comparison of the positive bending moments My for the $1^{\text {st }}$ and $3^{\text {rd }}$ iteration $-V=80 \mathrm{~km} / \mathrm{h}$ 
sign data of the Anhanguera bridge, object of study of this work. The second author acknowledges a grant from CNPq (3-2757/2013-9).

\section{References}

[1] SANTOS, E. F. Análise e redução de vibração em pontes rodoviárias. Doctoral Dissertation (in Portuguese), COPPE/ UFRJ, Rio de Janeiro, RJ, Brasil. 2007.

[2] ALMEIDA, R. S. Análise de vibrações em pontes rodoviárias induzidas pelo tráfego de veículos sobre pavimentos irregulares. Master Thesis (in Portuguese), UERJ, Rio de Janeiro, RJ, Brasil. 2006.

[3] WILLIS, R. Appendix to the Report of the Commissioners Appointed to Inquire into the Application of Iron to Railway Structures. Stationary Office, London. 1849.

[4] STOKES, G. Discussion of a differential equation relating to the breaking of railway bridges, Trans. Cambridge Philosophic Soc, v8. 1849.

[5] MELO, E.S Interação dinâmica veículo-estrutura em pequenas pontes rodoviárias. Master Thesis (in Portuguese), UERJ, Rio de Janeiro, RJ, Brasil. 2007.

[6] INGLIS, C.E. A Mathematical Treatise on Vibrations in Railway Bridges. Cambridge Univ. Press, London, 1934

[7] TIMOSHENKO, S., Vibration Problems in Engineering. 3rd Edition, D. Van. Nostrand. 1964.

[8] HUANG, T., VELETSOS, A.S. Analyses of Dynamic Response of Highway Bridges. ASCE, J. Mech, Div., 1970. Vol. 96.

[9] BRUCH, Y.A. Análise Dinâmica de Placas Retangulares pelo Método dos Elementos Finitos. Master Thesis (in Portuguese), COPPE/UFRJ. RJ, Brasil, 1973

[10] CARNEIRO, R.J.F.M. Análise de Pontes Rodoviárias sob Ação de Cargas Móveis. Master Thesis (in Portuguese), PUC-Rio, Rio de Janeiro, RJ, Brasil. 1986.

[11] FERREIRA, K.I.I. Avaliação do Critério para Cálculo dos Efeitos de Cargas Móveis em Pontes Rodoviárias. Master Thesis (in Portuguese), PUC-Rio, RJ, Brasil. 1991.

[12] CHANG, D., LEE, H., Impact Factors for Simple-Span Highway Girder Bridges. Journal of Structural Engineering, ASCE, v.120, n.3, pp704-715.

[13] NOWAK, A.S. Load Model for Bridge Design Code. Canadian Journal of Civil Engineering., v21, pp.36-49. 1994.

[14] MOROZ, F. V. Uma metodologia para análise da influência do tráfego de veículos pesados na resposta dinâmica de pontes rodoviárias. Master Thesis (in Portuguese), EPUSP, São Paulo, SP, Brasil. 2009.

[15] ROSSIGALI, C. E. Estudos probabilísticos para modelos de cargas móveis em pontes rodoviárias no Brasil. Master Thesis (in Portuguese), COPPE/UFRJ, Rio de Janeiro, RJ, Brasil. 2006.

[16] Atualização do modelo de cargas móveis para pontes rodoviárias de pequenos vão no Brasil. Doctoral Dissertation (in Portuguese), COPPE/UFRJ, Rio de Janeiro, RJ, Brasil. 2013.

[17] ADINA - Automatic Dynamic Incremental Nonlinear Analysis Software: version 9.0.1. Developed by ADINA R\&D, Inc. Massachusetts, 2013. Available at: http://www.adina.com. Access in 06/02/2015.
[18] HONDA, H., KAJIKAWA, Y., KOBORI, T., Spectra of Road Surface Roughness on Bridges. Journal of the Structural Division, ASCE, v108, ST9, pp 1956-1996, 1982

[19] EJZENBERG, S. Os veículos pesados e a segurança no projeto das curvas horizontais de rodovias e vias de transito rápido. Master Thesis (in Portuguese), EPUSP, São Paulo, SP, Brasil. 2009.

[20] YANG, Y, LIN, B. Vehicle-Bridge Interaction Analysis by Dynamic Condensation Method. Journal of Structural Engineering, ASCE, v121, pp 1636-1643, 1995.

[21] CAMPOS, A.C.R., Métodos de Previsão de Desempenho de Irregularidade Longitudinal para Pavimentos asfálticos: Aplicação e Proposição de Critérios de Ajuste. Master Thesis (in Portuguese), Campinas State University, Campinas, SP, Brasil, 2004. 